Intermediate diol $2\left({ }^{1} \mathrm{H}\right)$

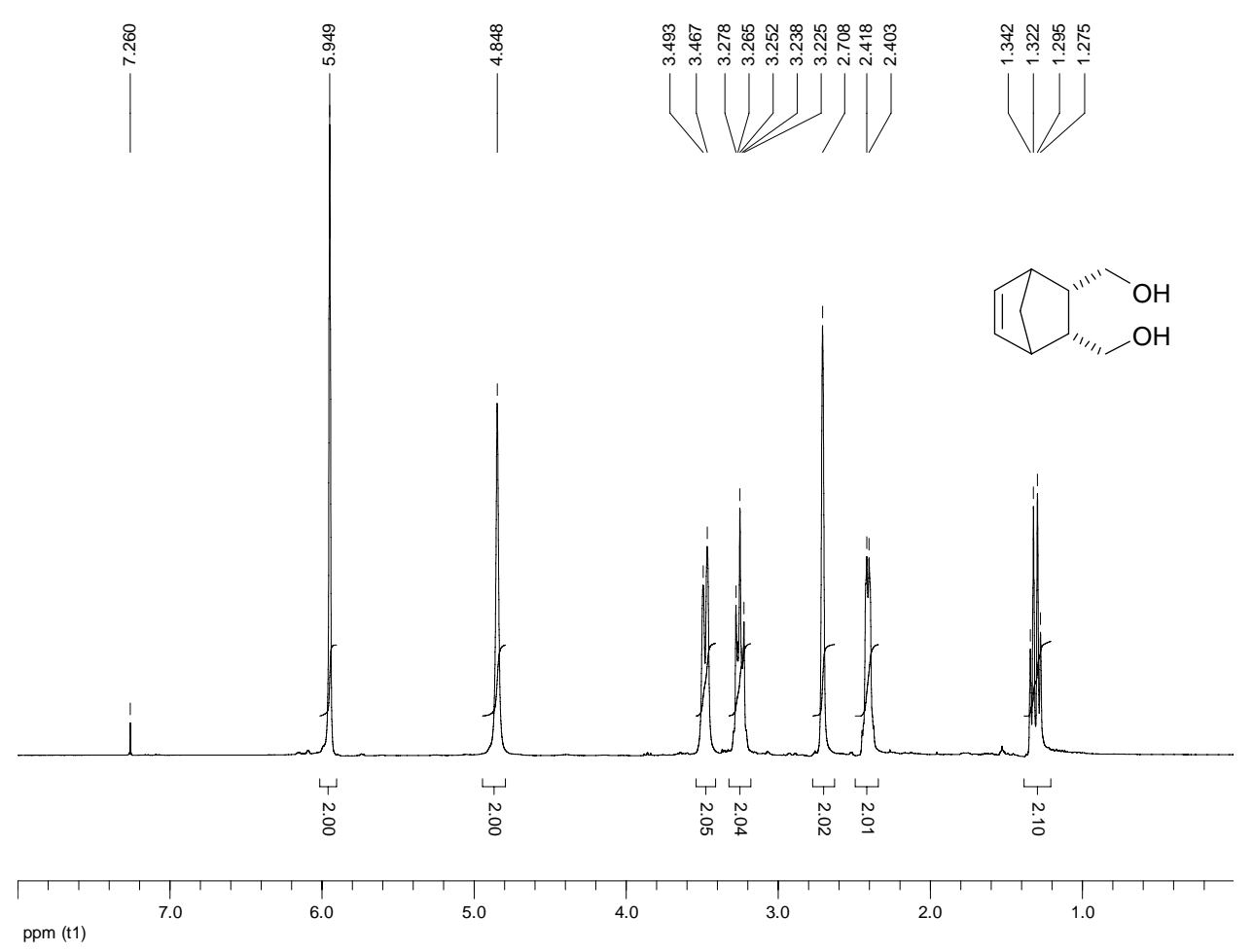

Intermediate diol $2\left({ }^{13} \mathrm{C}\right)$
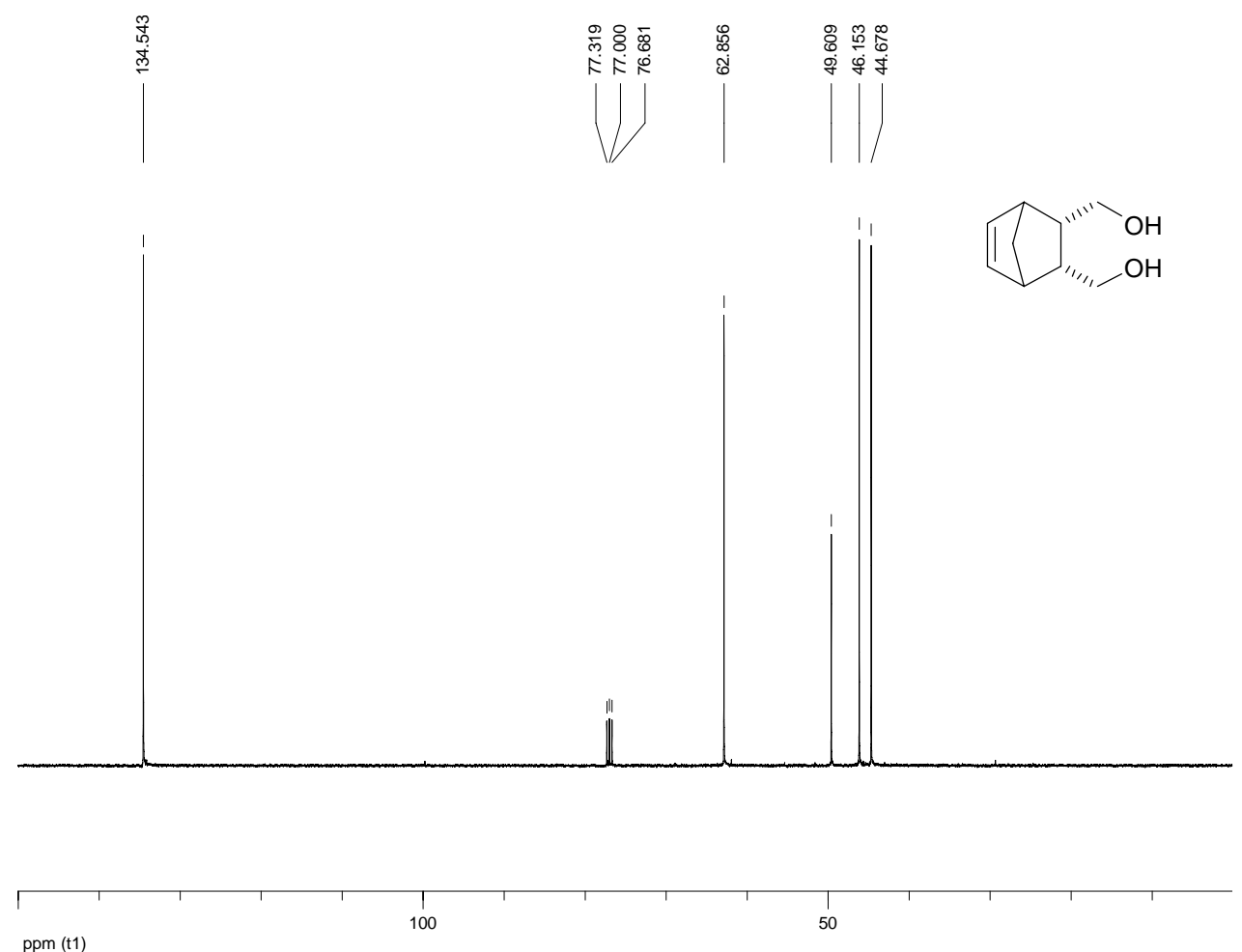
Intermediate bismesylate $3\left({ }^{1} \mathrm{H}\right)$
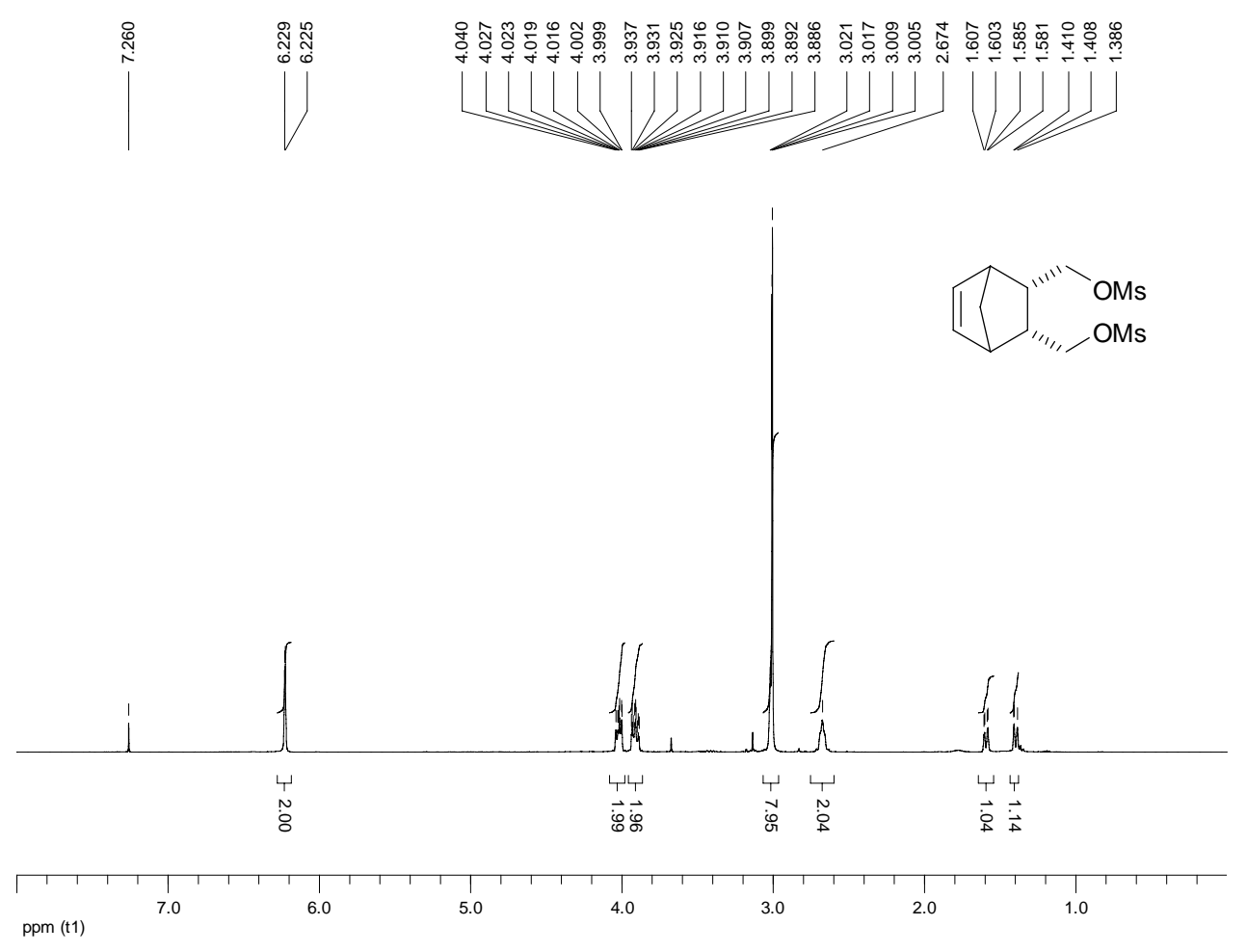

Intermediate bismesylate $3\left({ }^{13} \mathrm{C}\right)$
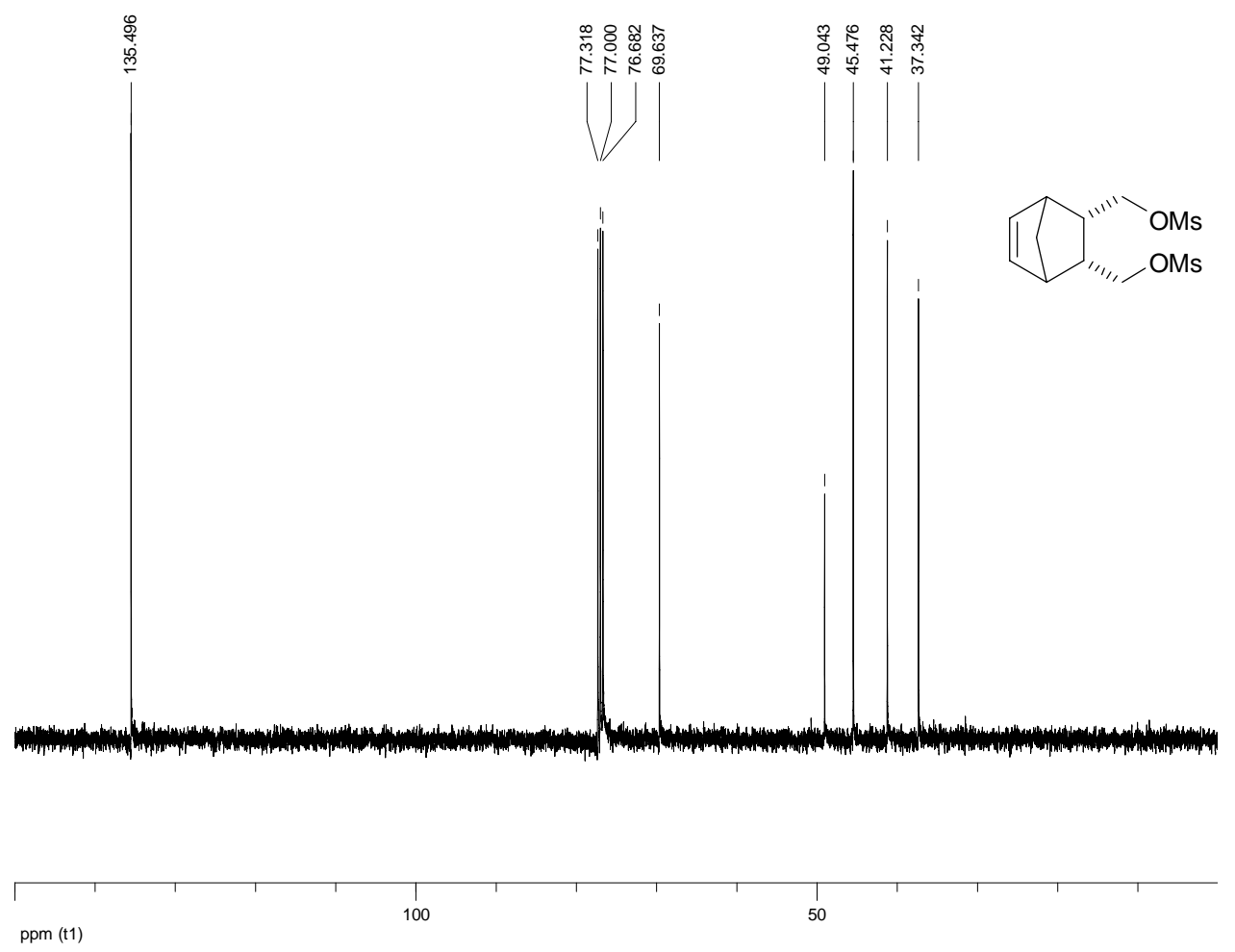


\section{Sulfide $4\left({ }^{1} \mathrm{H}\right)$}

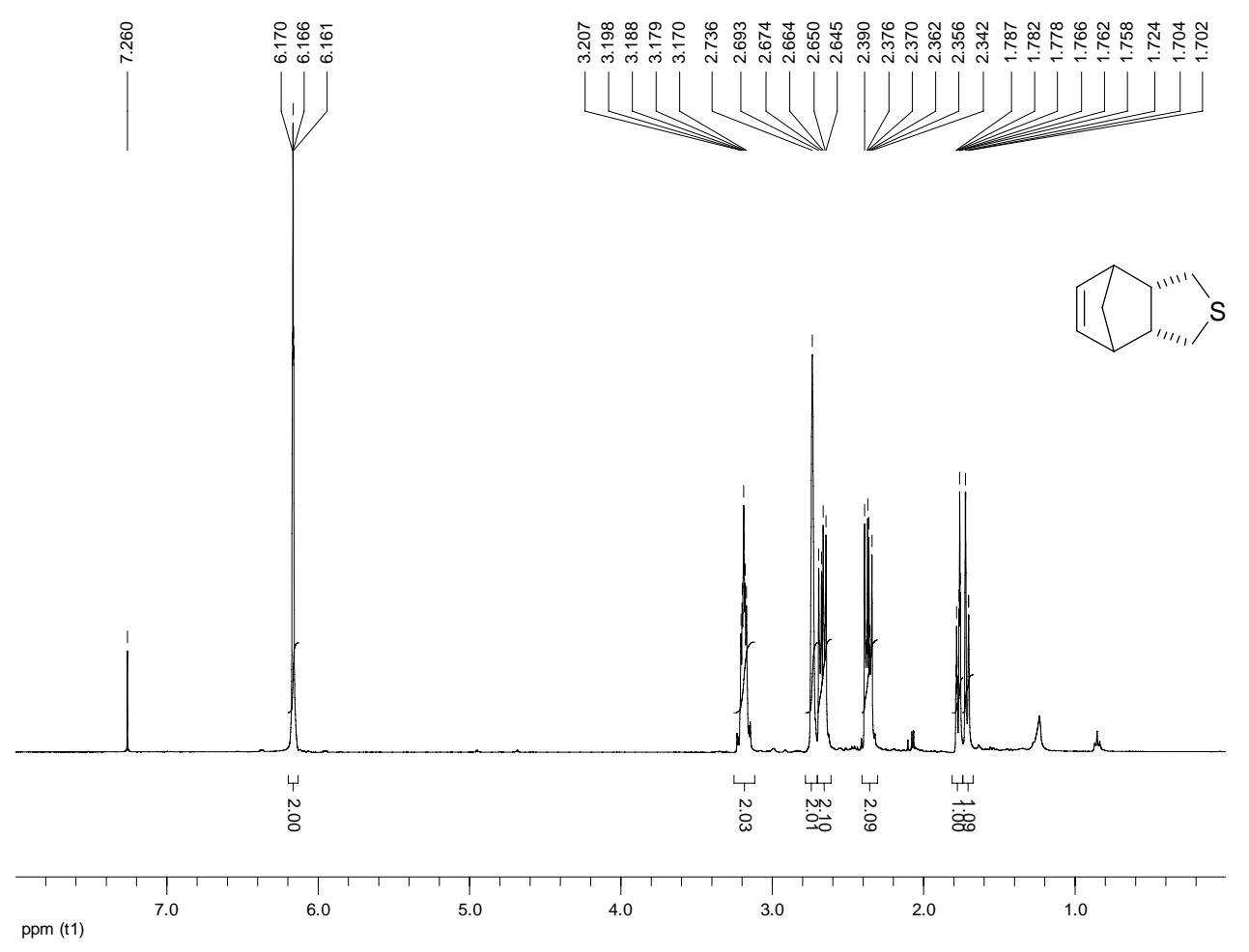

Sulfide $4\left({ }^{13} \mathrm{C}\right)$
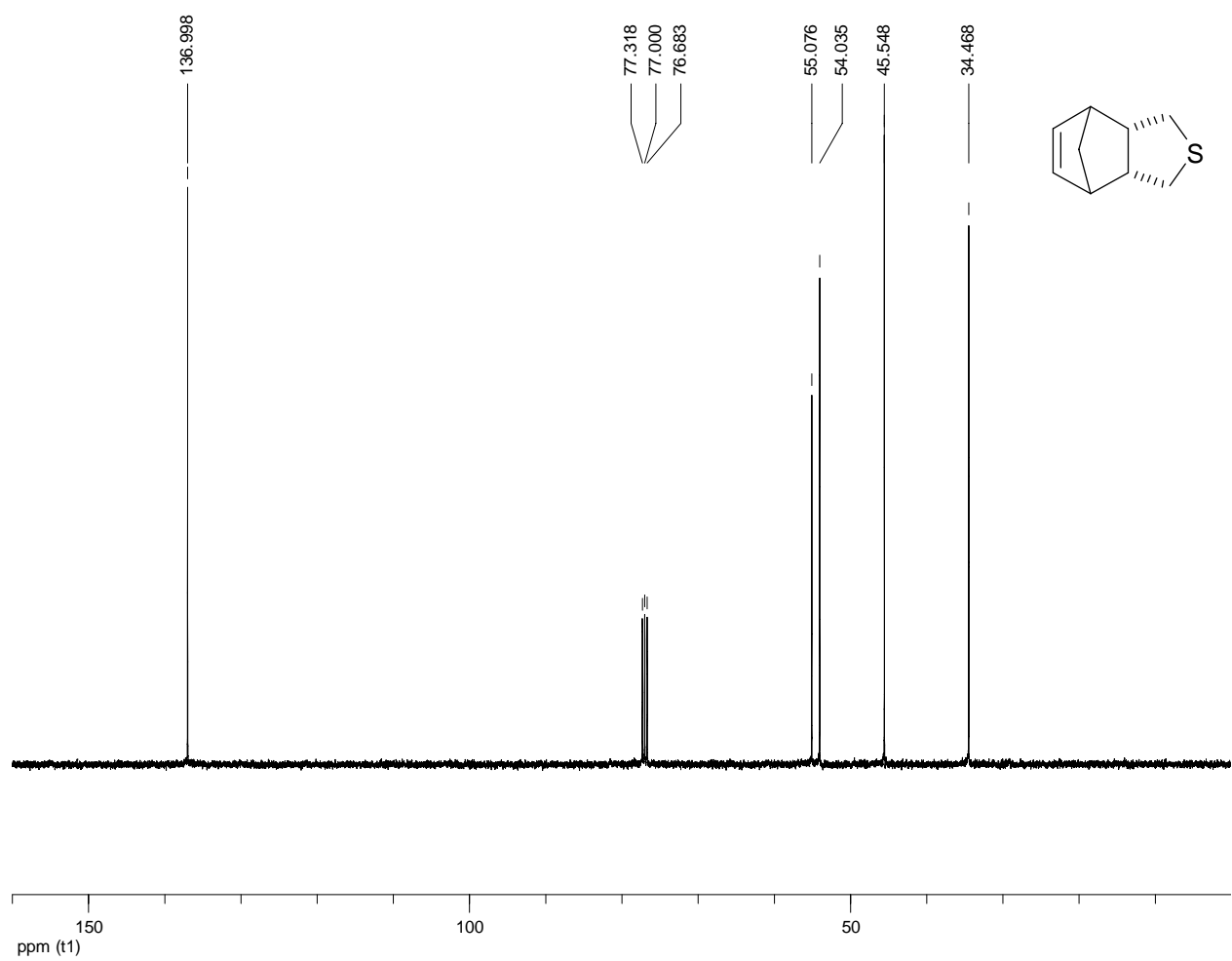


\section{Monomer 5a $\left({ }^{1} \mathrm{H}\right)$}

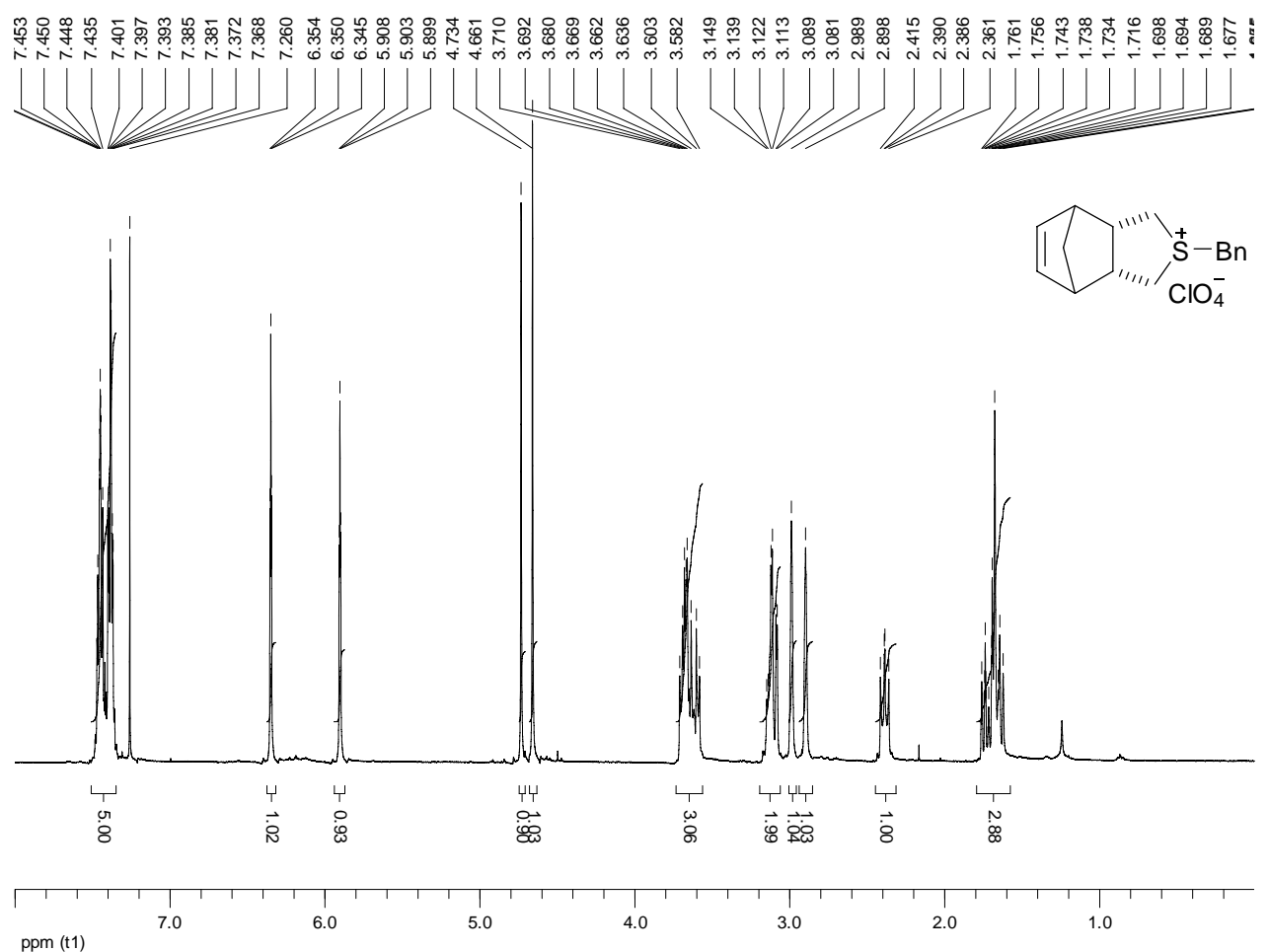

Monomer 5a $\left({ }^{13} \mathrm{C}\right)$

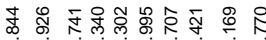

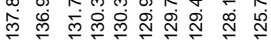
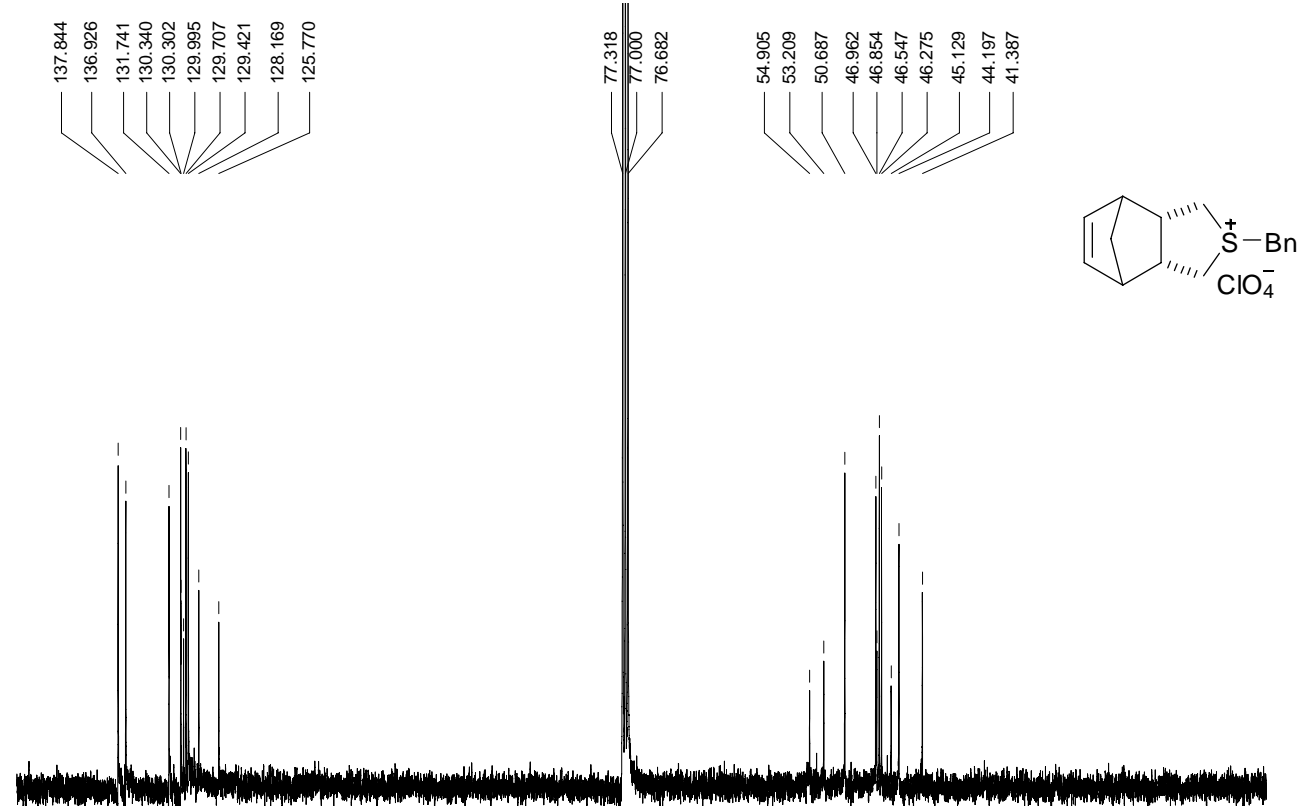

(n)

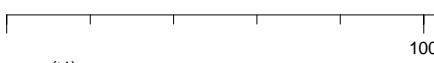

ppm (t1) 


\section{Monomer $5 \mathbf{b}\left({ }^{1} \mathrm{H}\right)$}
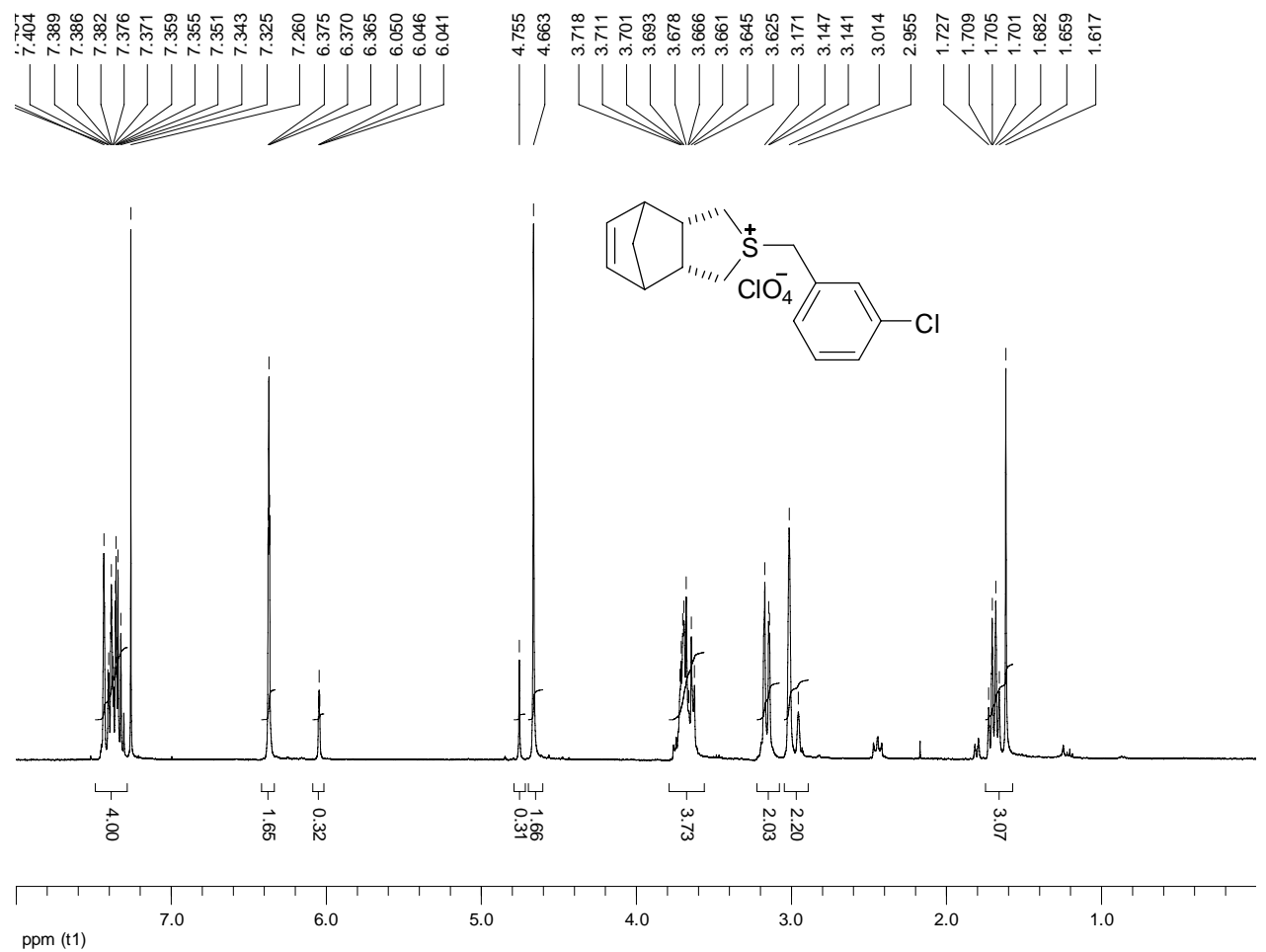

Monomer $5 \mathbf{b}\left({ }^{13} \mathrm{C}\right)$

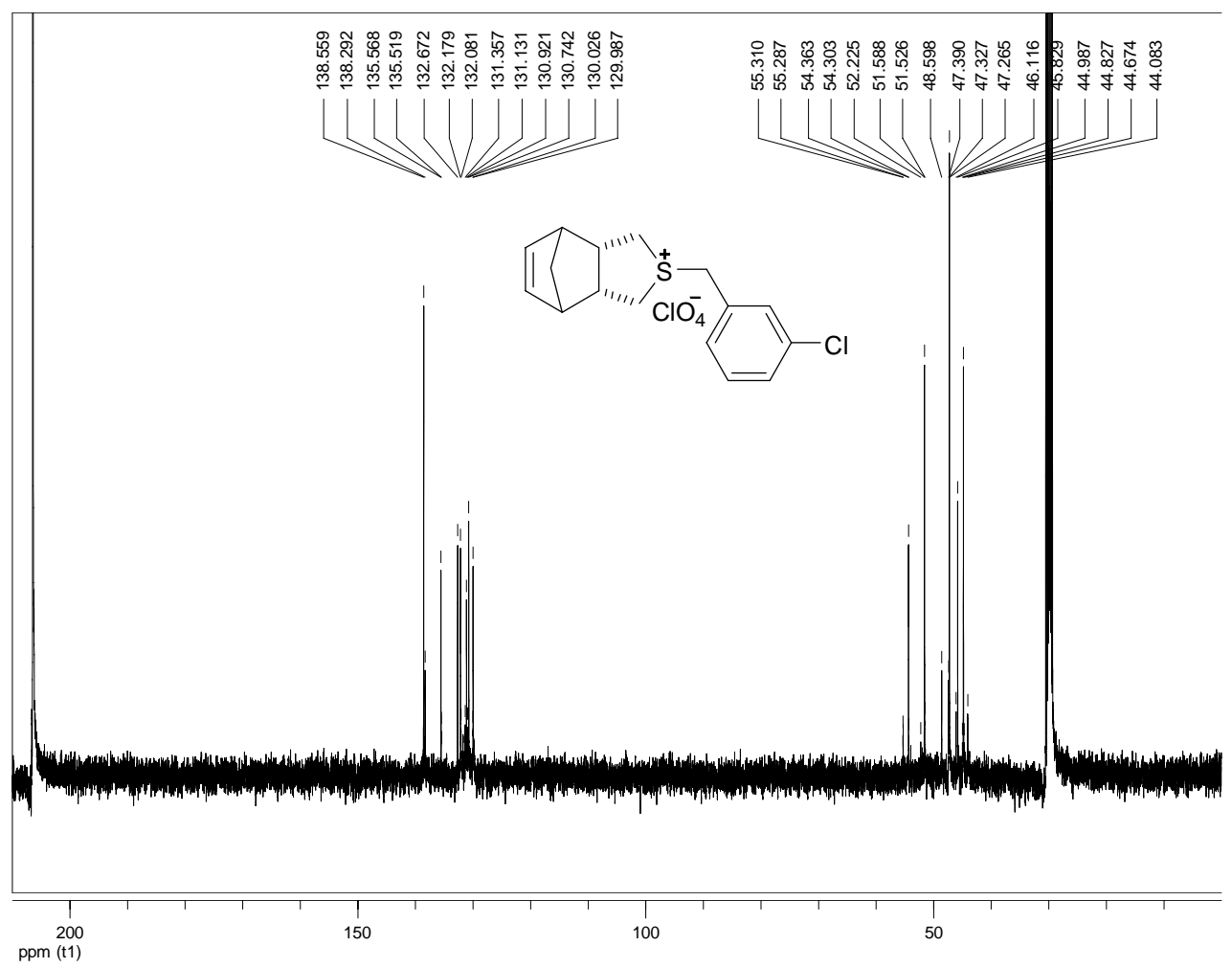




\section{Monomer 5c $\left({ }^{1} \mathrm{H}\right)$}

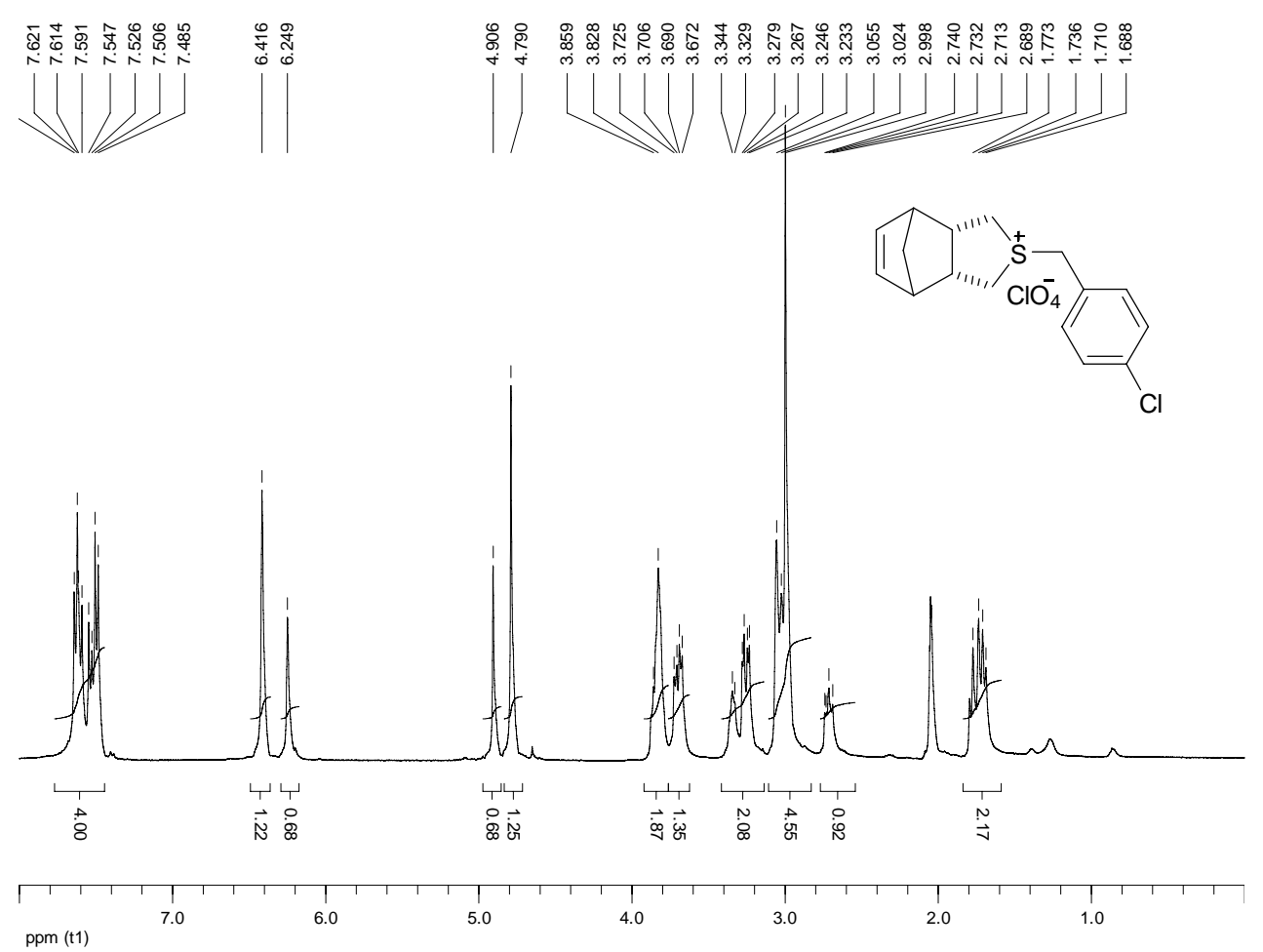

Monomer 5c $\left({ }^{13} \mathrm{C}\right)$
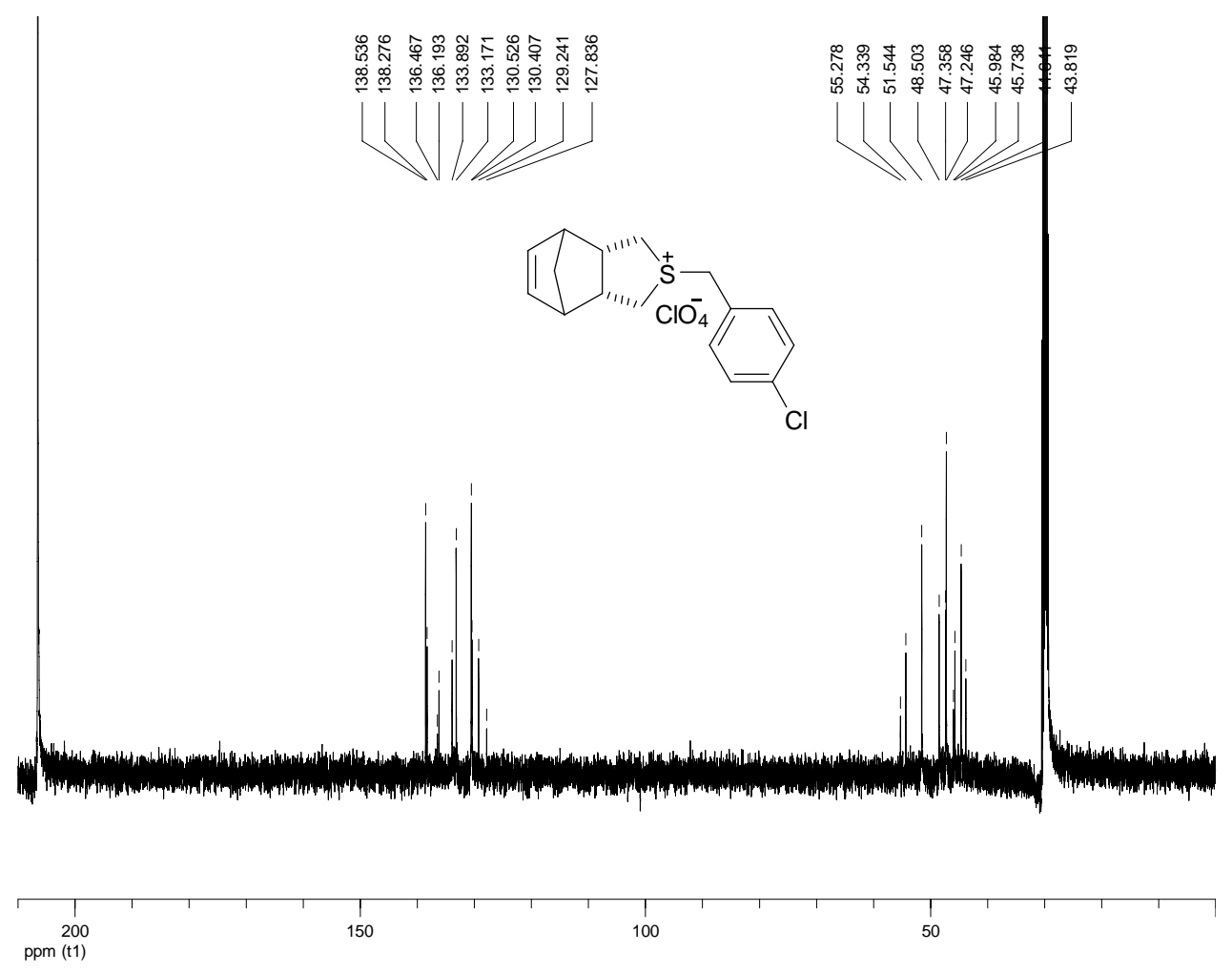


\section{Monomer 5d $\left({ }^{1} \mathrm{H}\right)$}

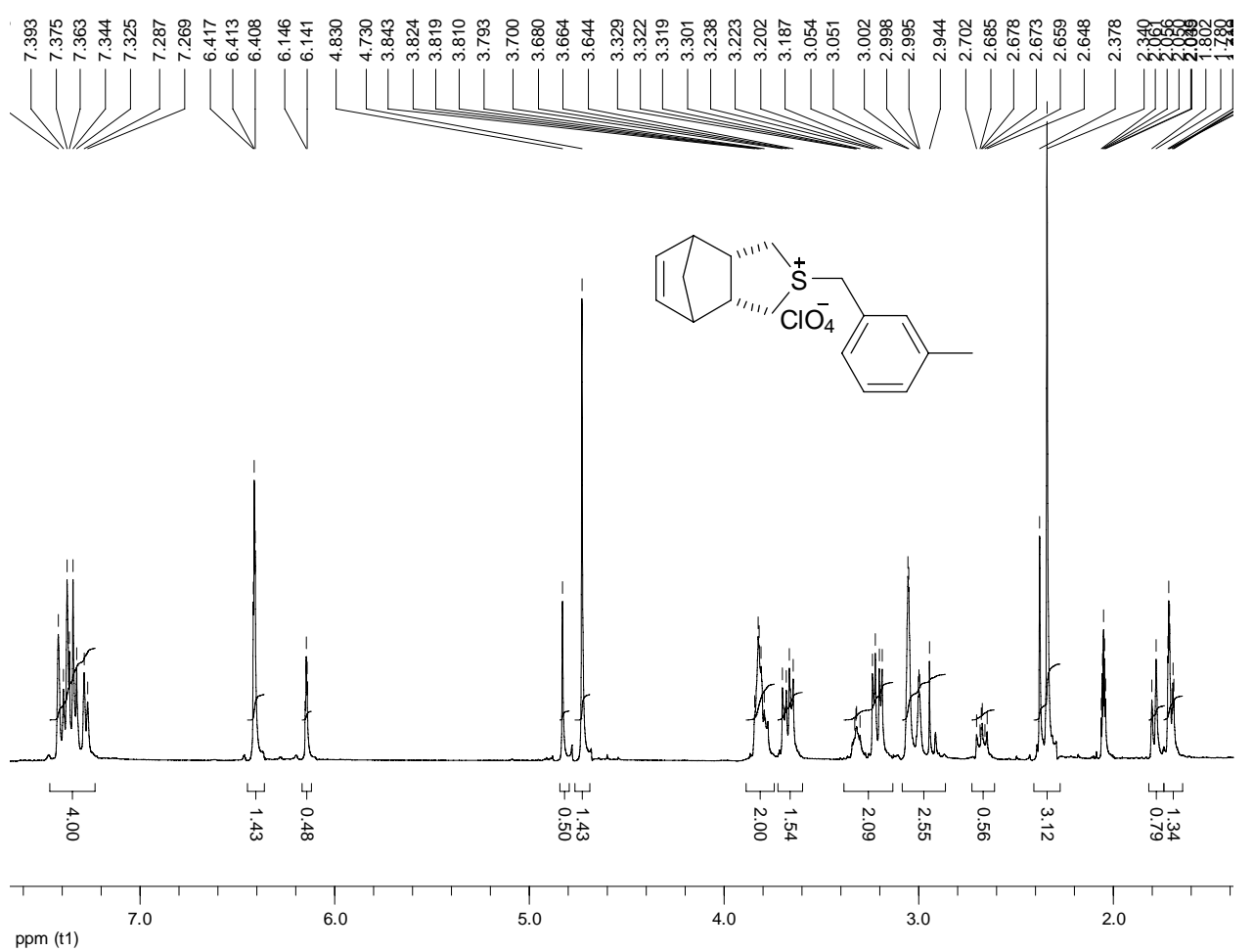

Monomer 5d $\left({ }^{13} \mathrm{C}\right)$
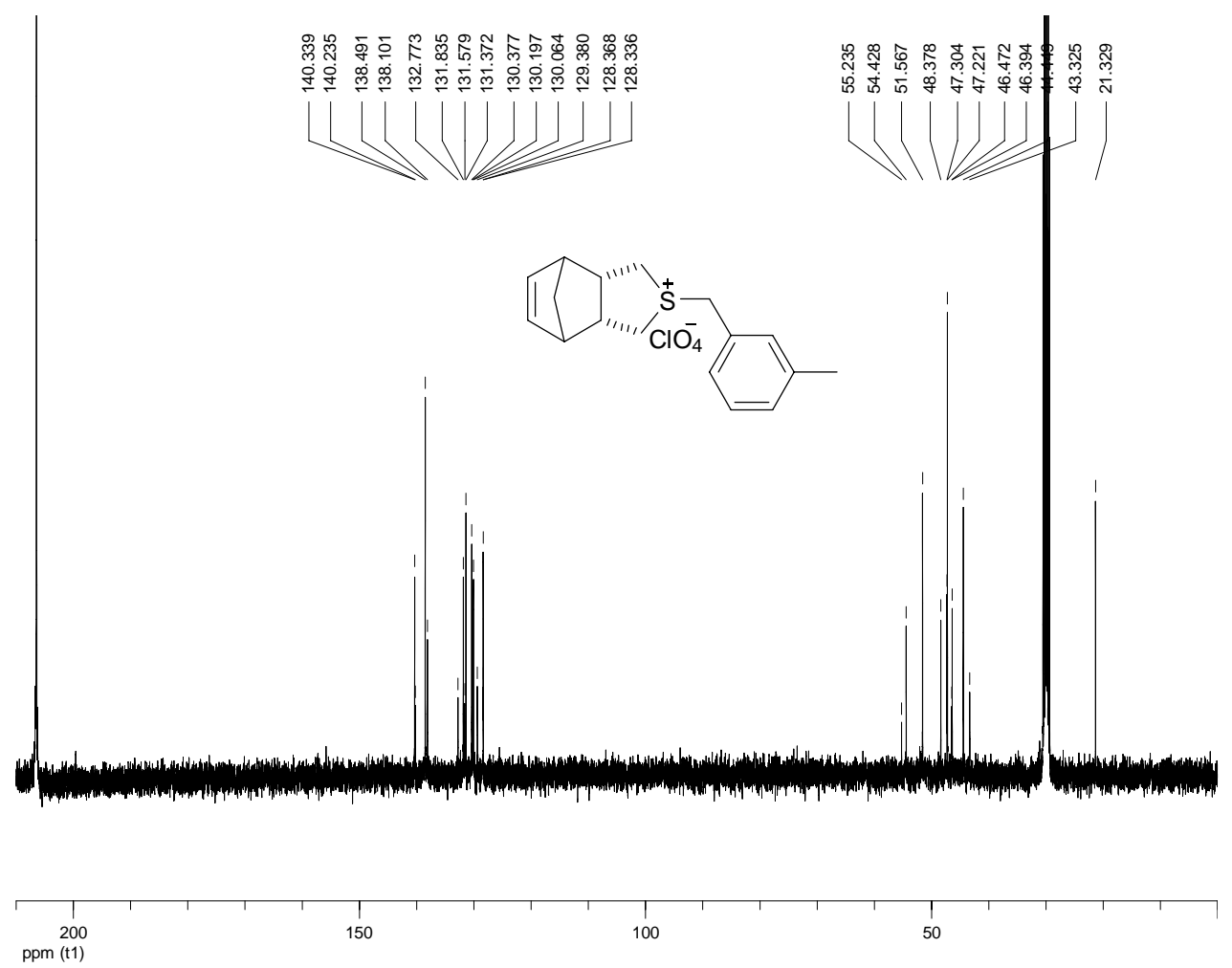


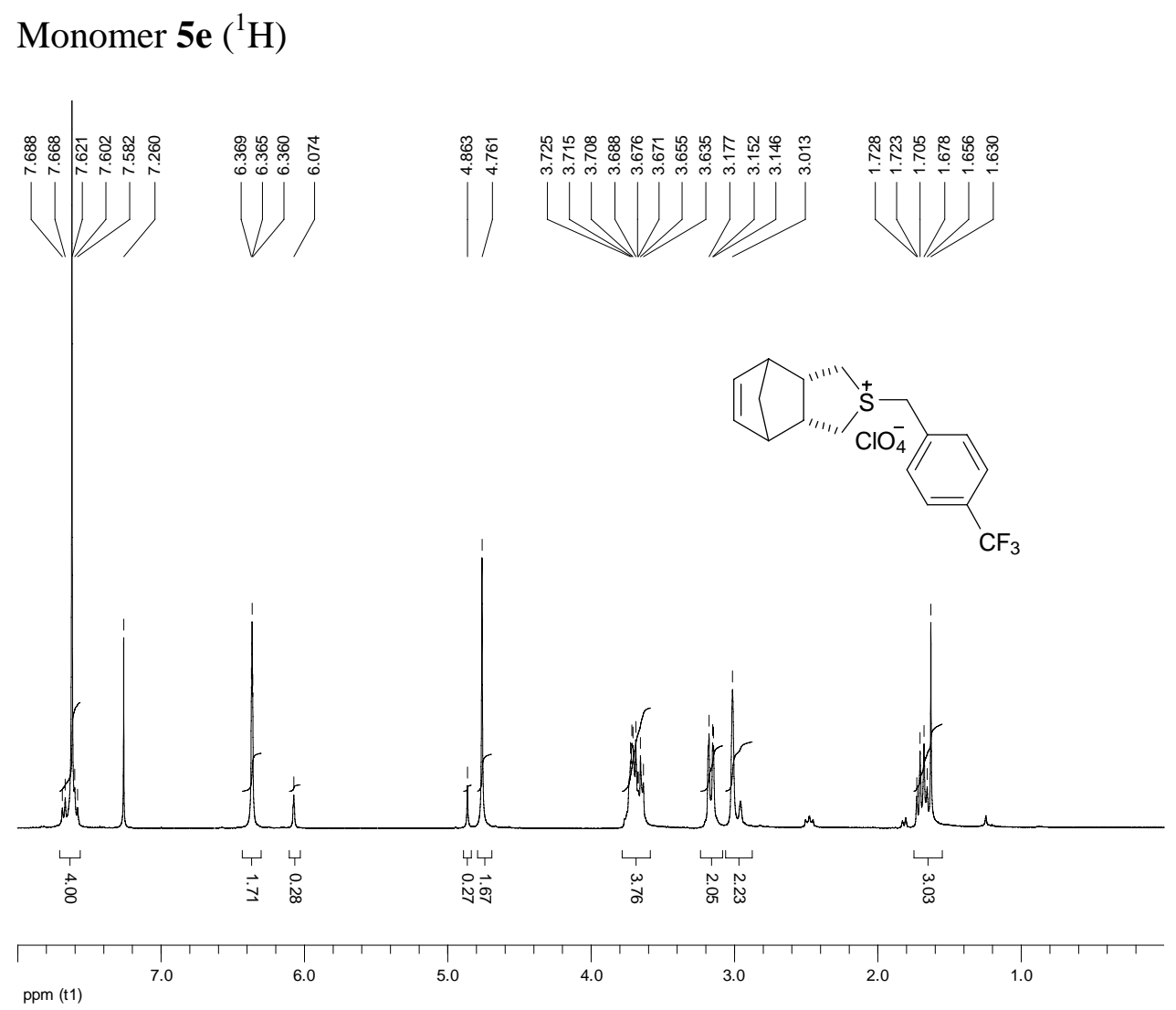

Monomer 5e $\left({ }^{13} \mathrm{C}\right)$
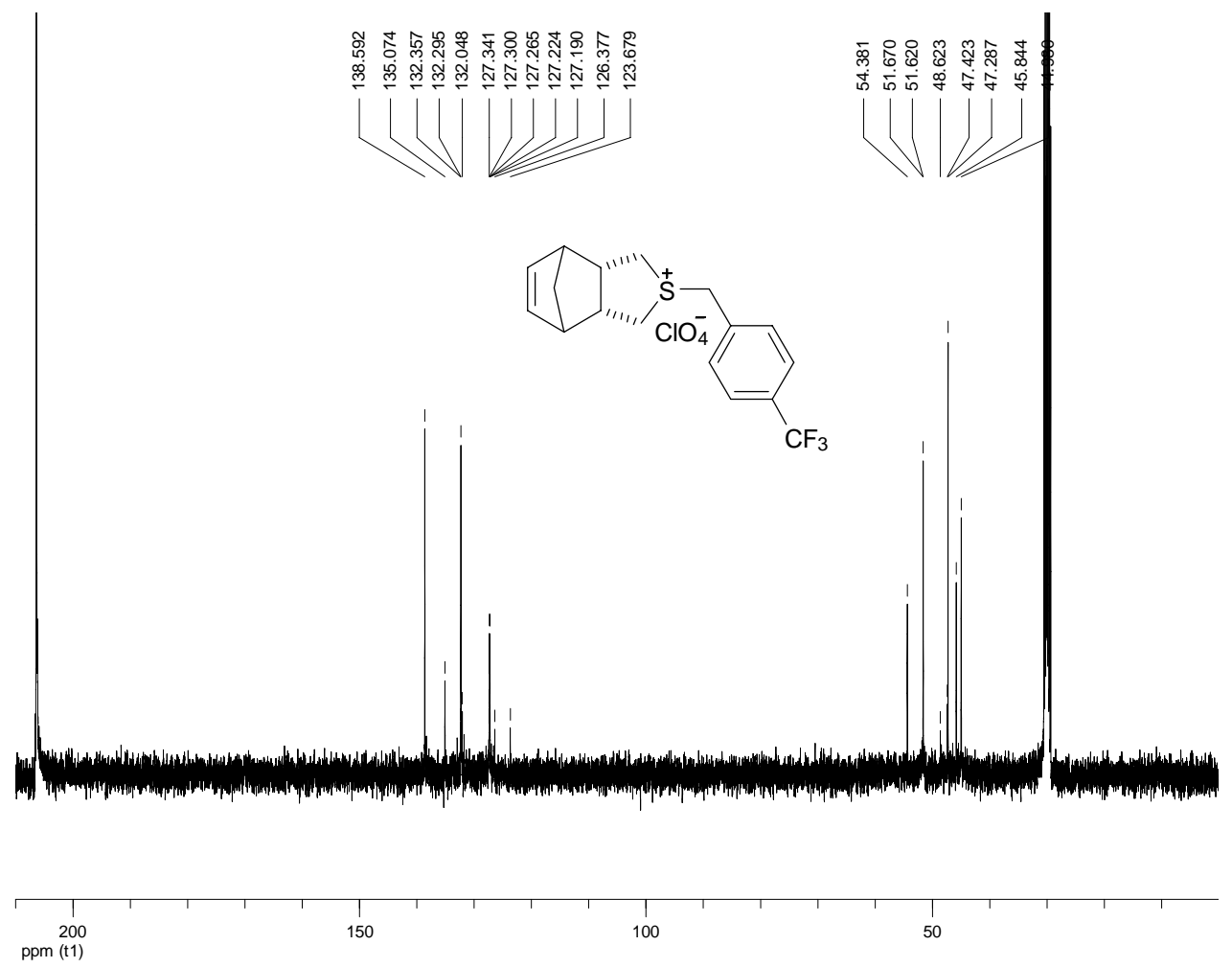
Product 8a, Table 1, Entry 1; Table 2, Entry 1, 2; Table 4, Entry $4\left({ }^{1} \mathrm{H}\right)$

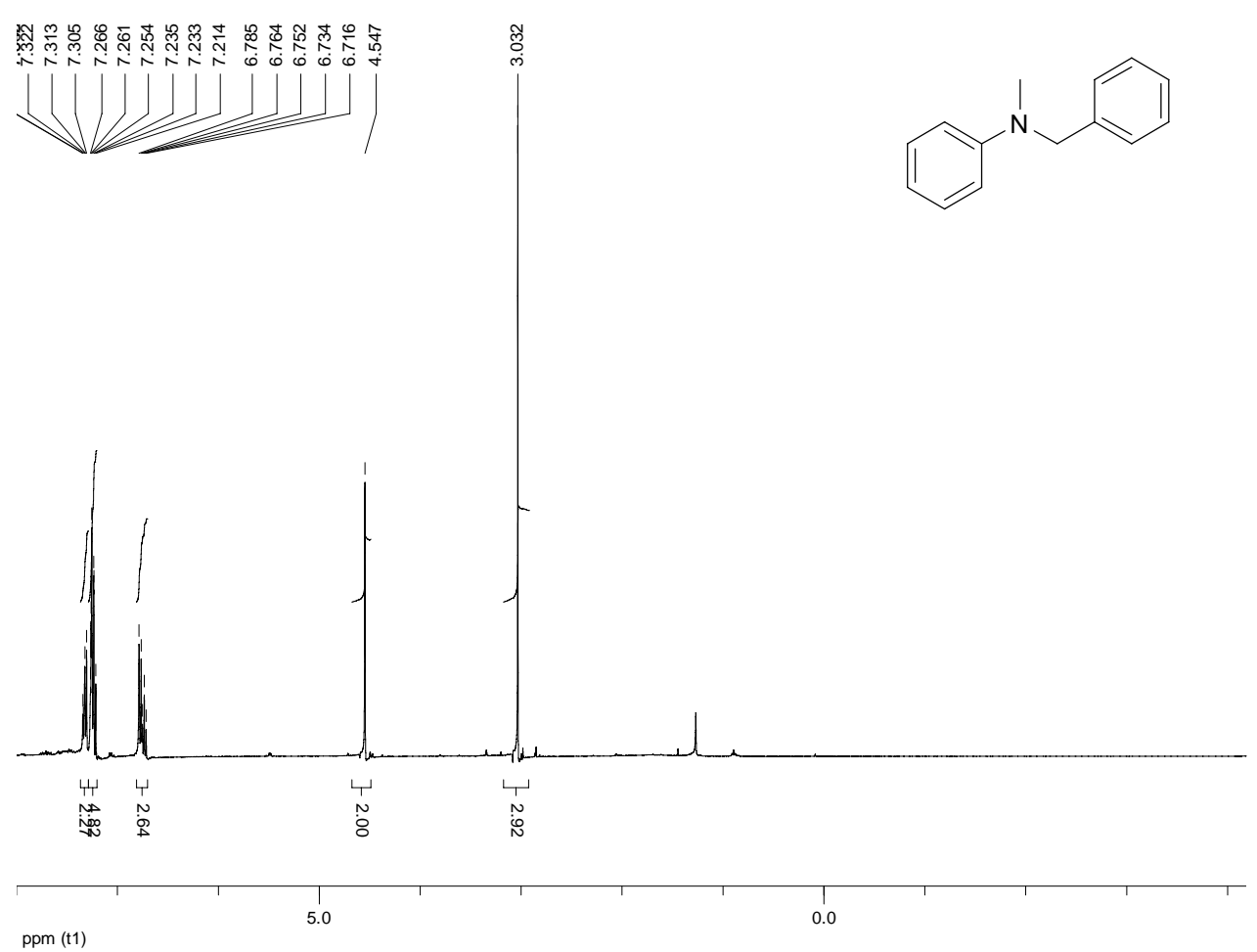

Product 8b, Table 1, Entry 2; Table 4, Entry $5\left({ }^{1} \mathrm{H}\right)$

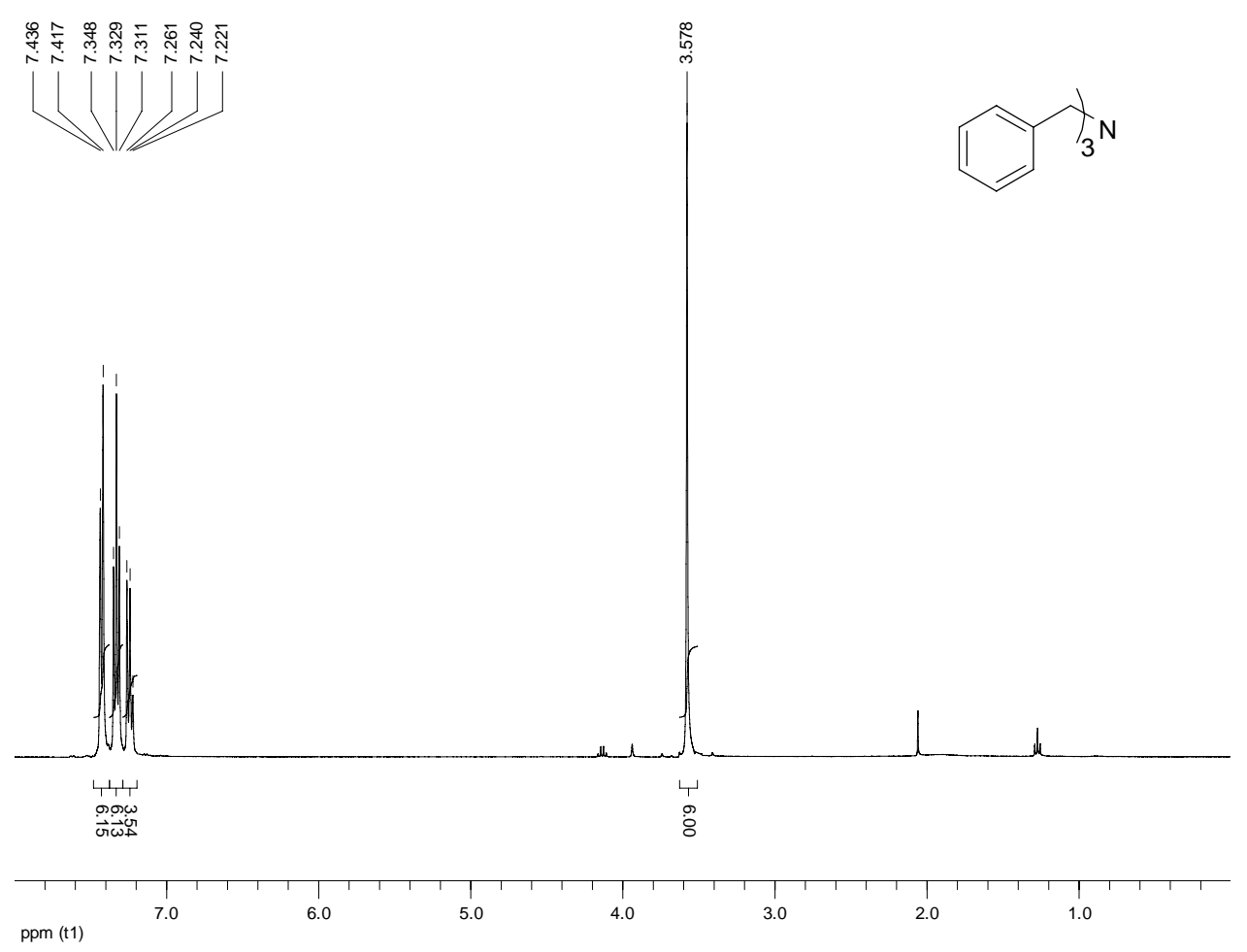


Product 8c, Table 1, Entry 3; Table 2, Entry 3; Table 4, Entry $6\left({ }^{1} \mathrm{H}\right)$

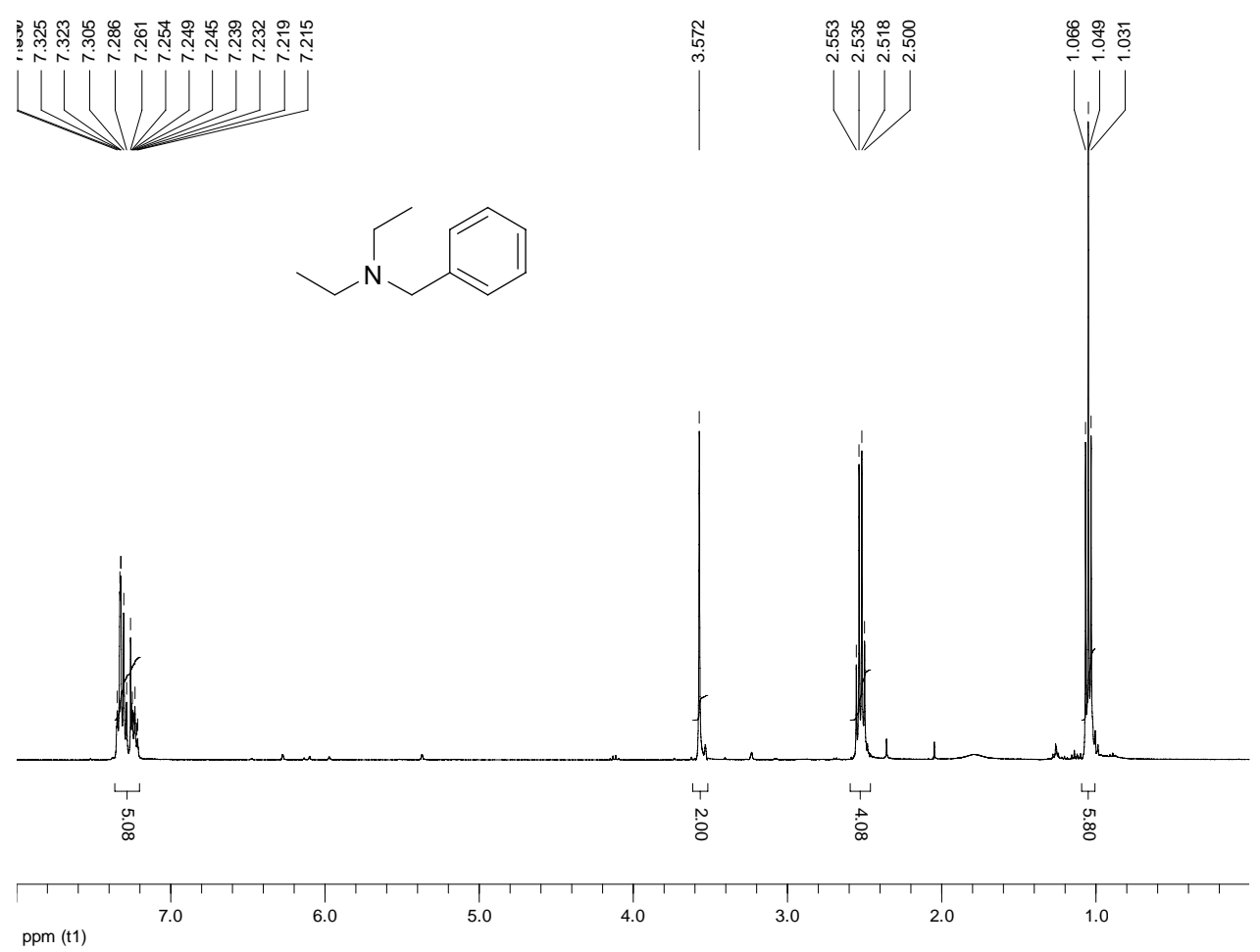

Product 8d, Table 1, Entry 4; Table 3, Entry $1\left({ }^{1} \mathrm{H}\right)$
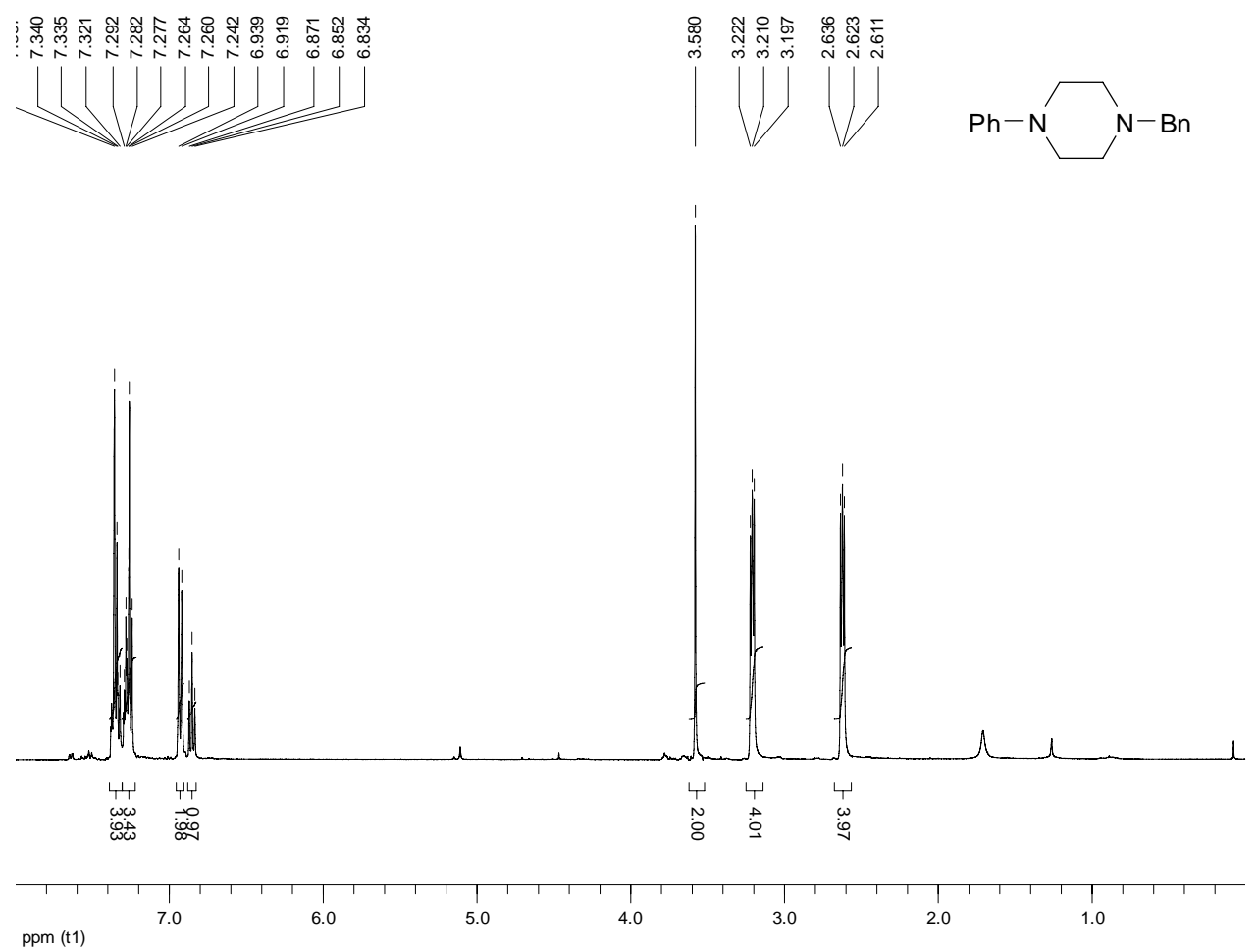
Product 8e, Table 1, Entry 5; Table 5, Entry $1\left({ }^{1} \mathrm{H}\right)$

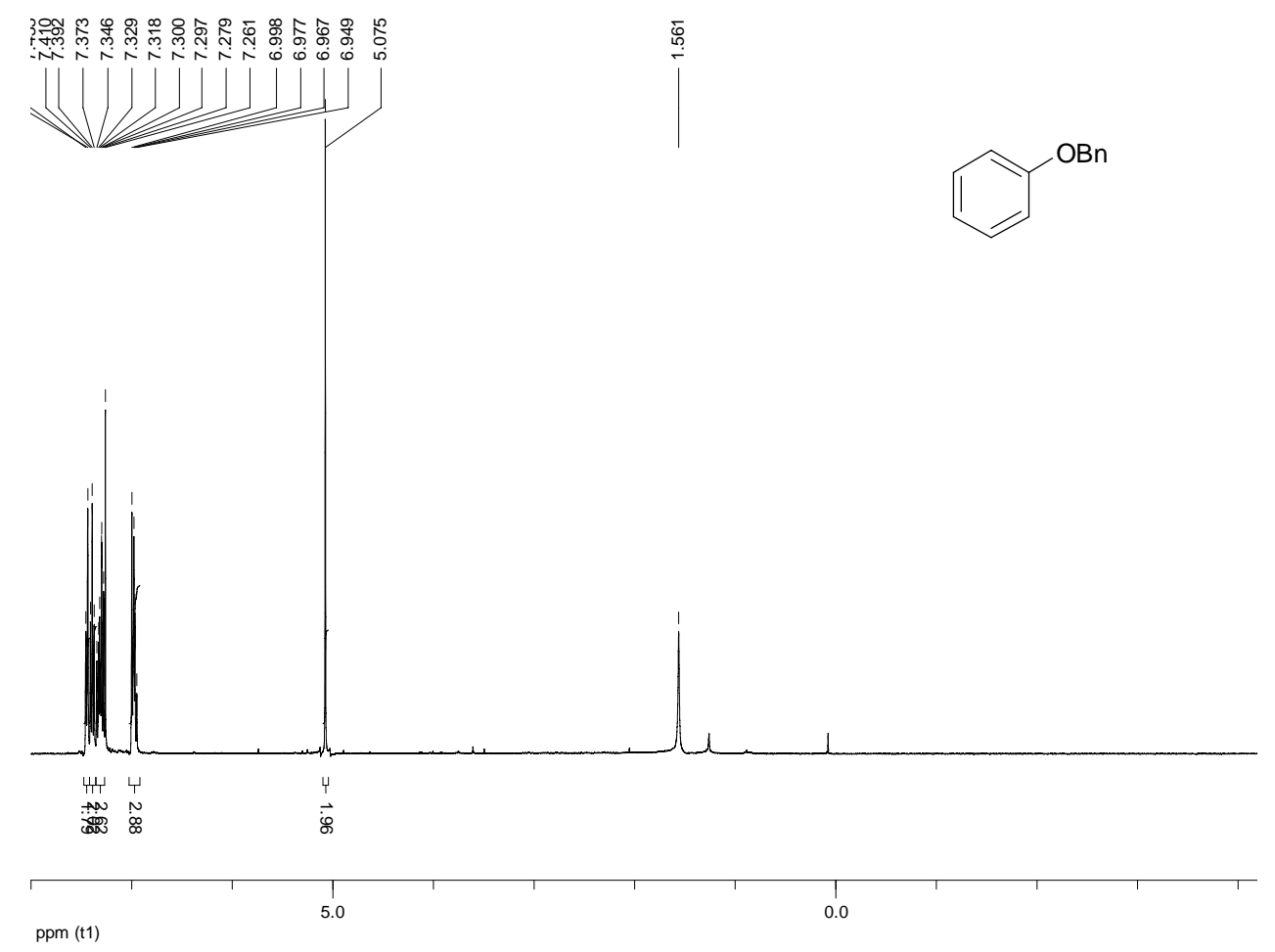

Product 9, Table 2, Entry $4\left({ }^{1} \mathrm{H}\right)$

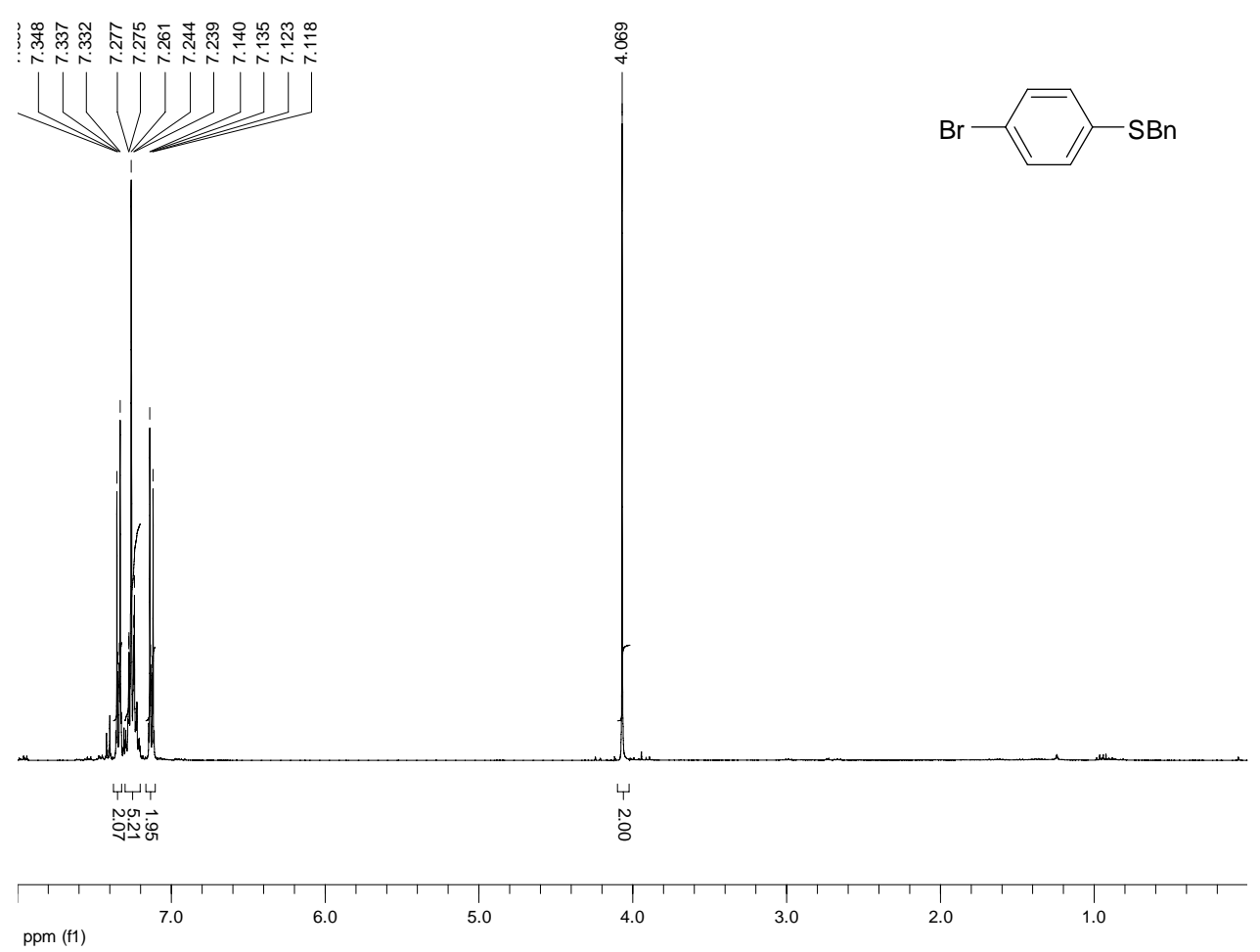


Product 10a, Table 3, Entry $2\left({ }^{1} \mathrm{H}\right)$

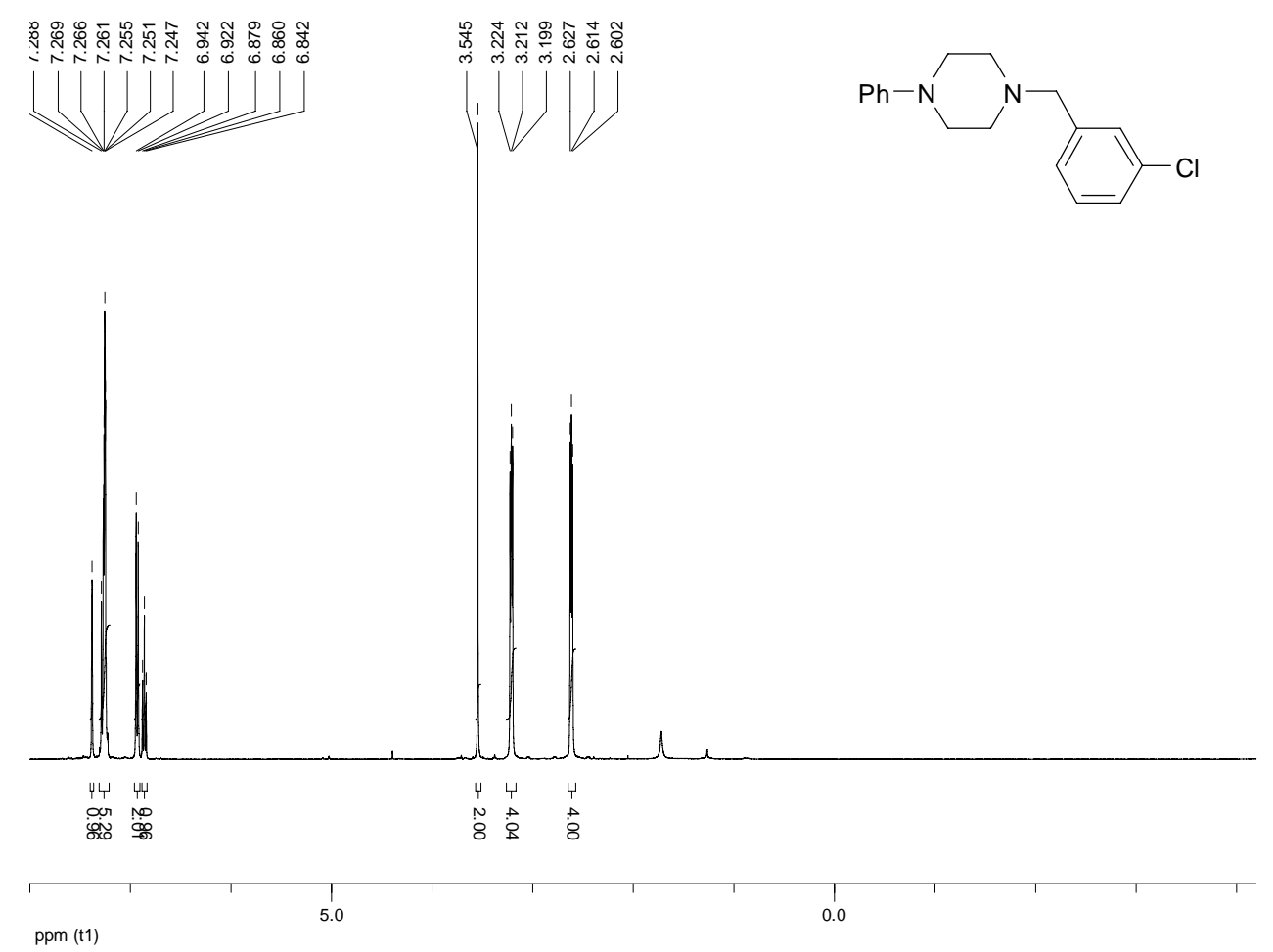

Product 10b, Table 3, Entry $3\left({ }^{1} \mathrm{H}\right)$

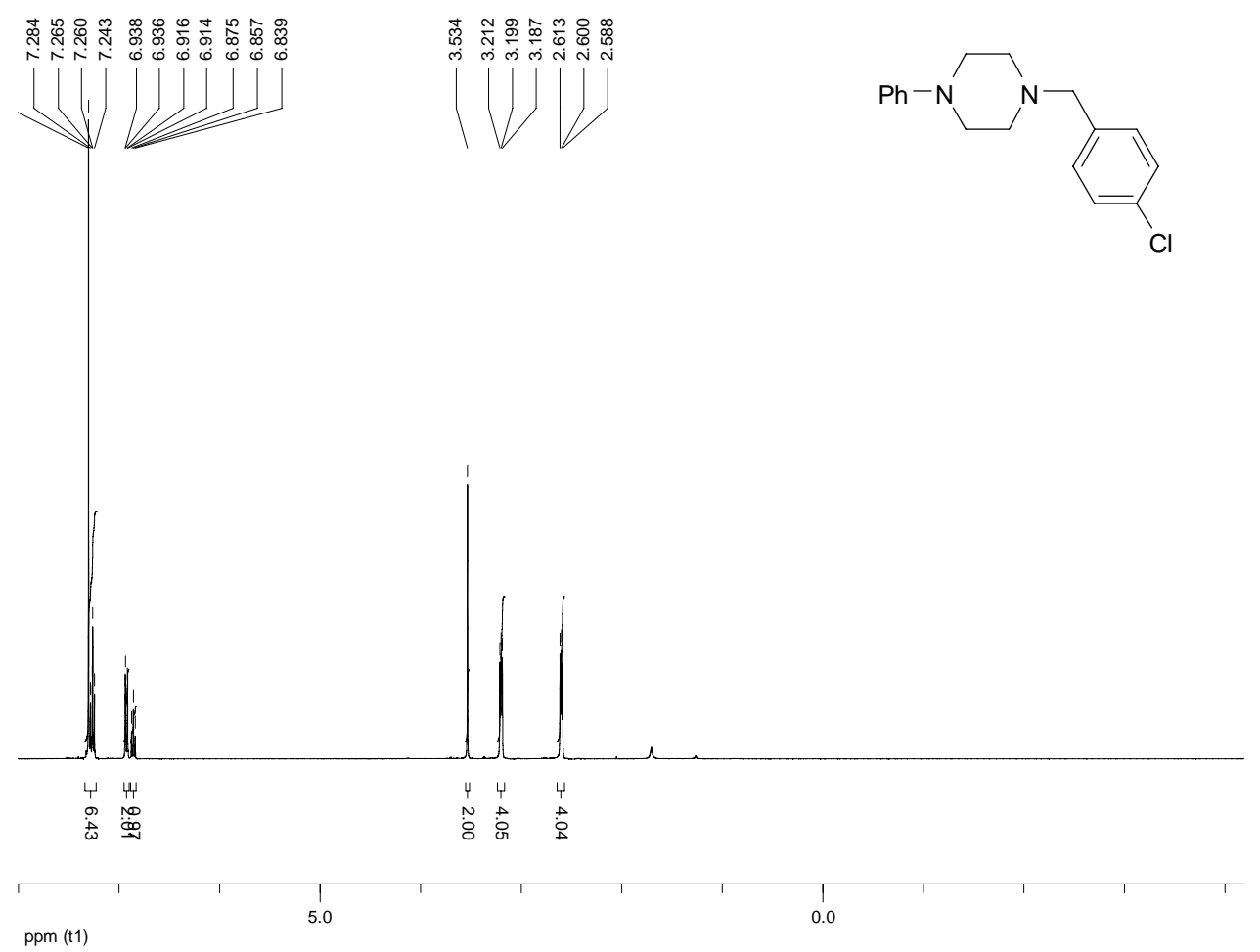


Product 10c, Table 3, Entry $4\left({ }^{1} \mathrm{H}\right)$

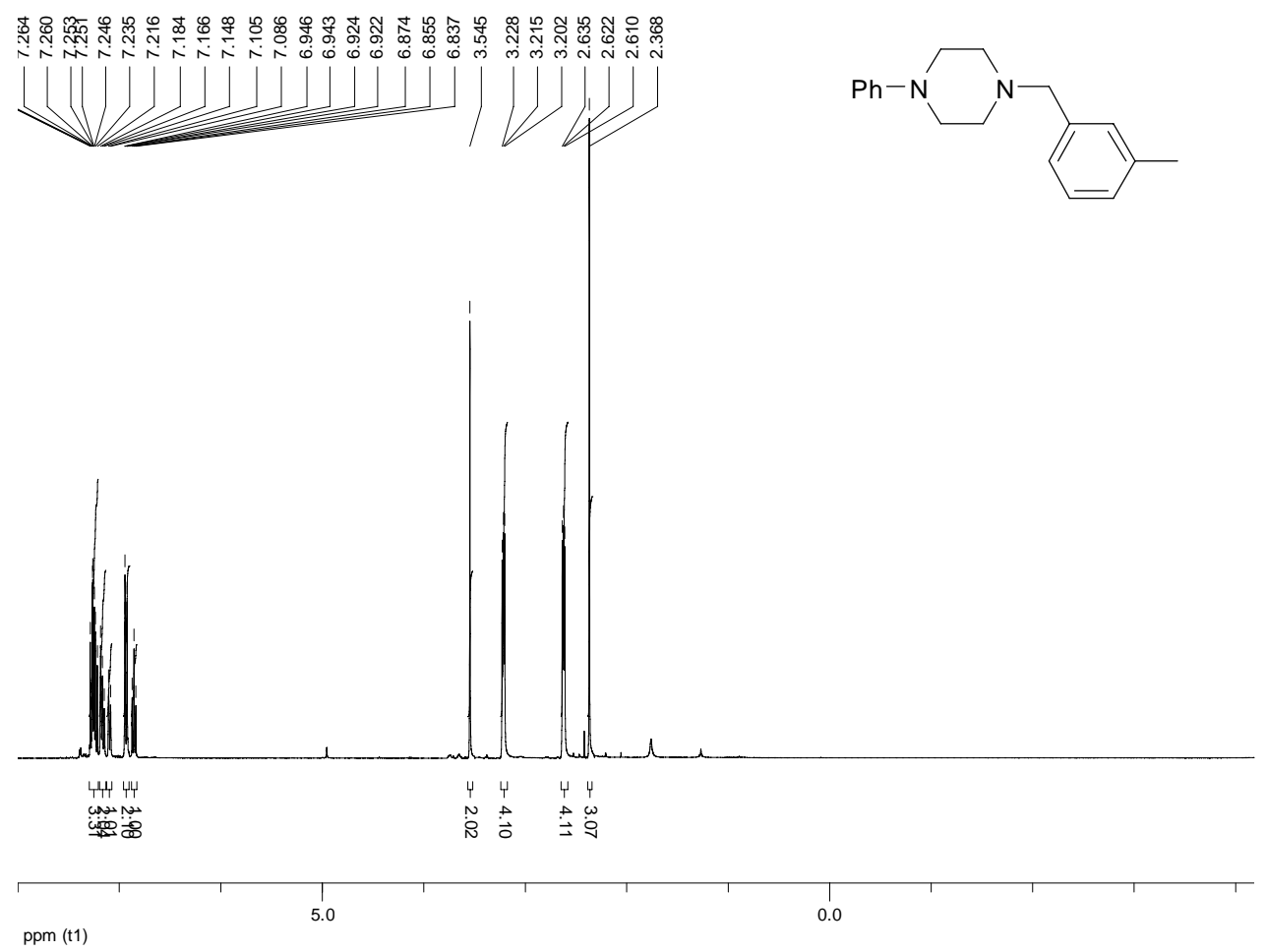

Product 10d, Table 3, Entry $5\left({ }^{1} \mathrm{H}\right)$

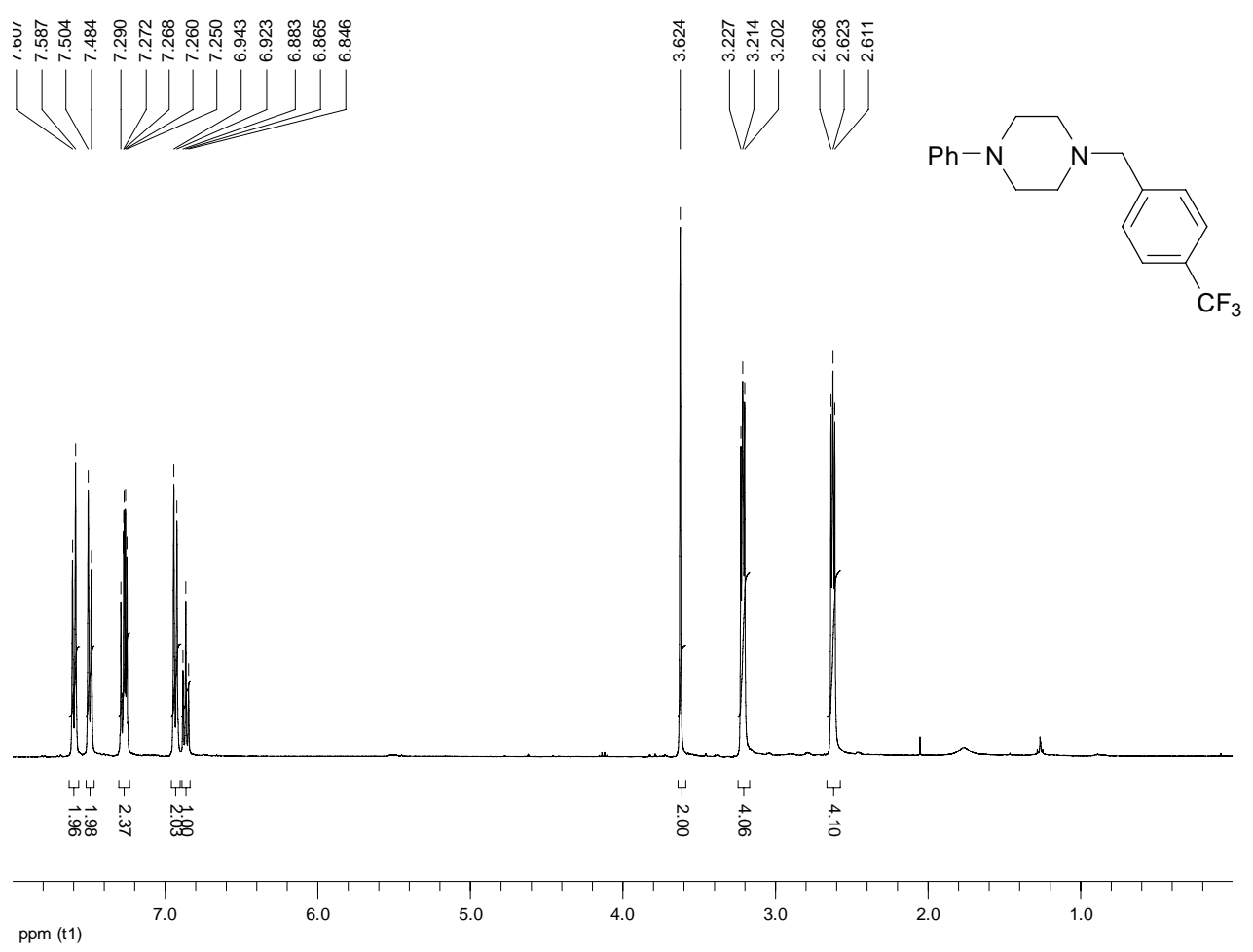


Product 11a, Table 4, Entry $1\left({ }^{1} \mathrm{H}\right)$

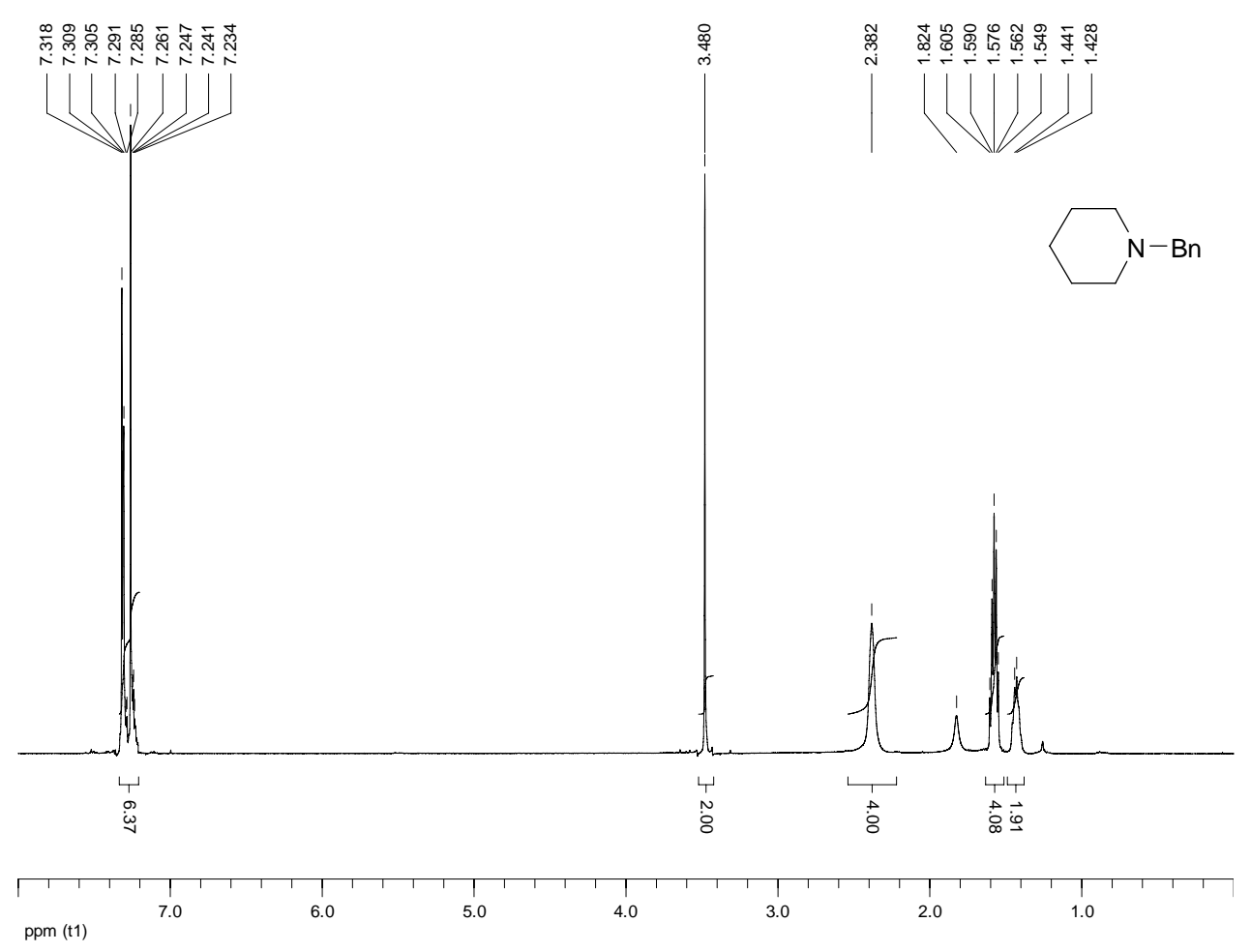

Product 11b, Table 4, Entry $2\left({ }^{1} \mathrm{H}\right)$

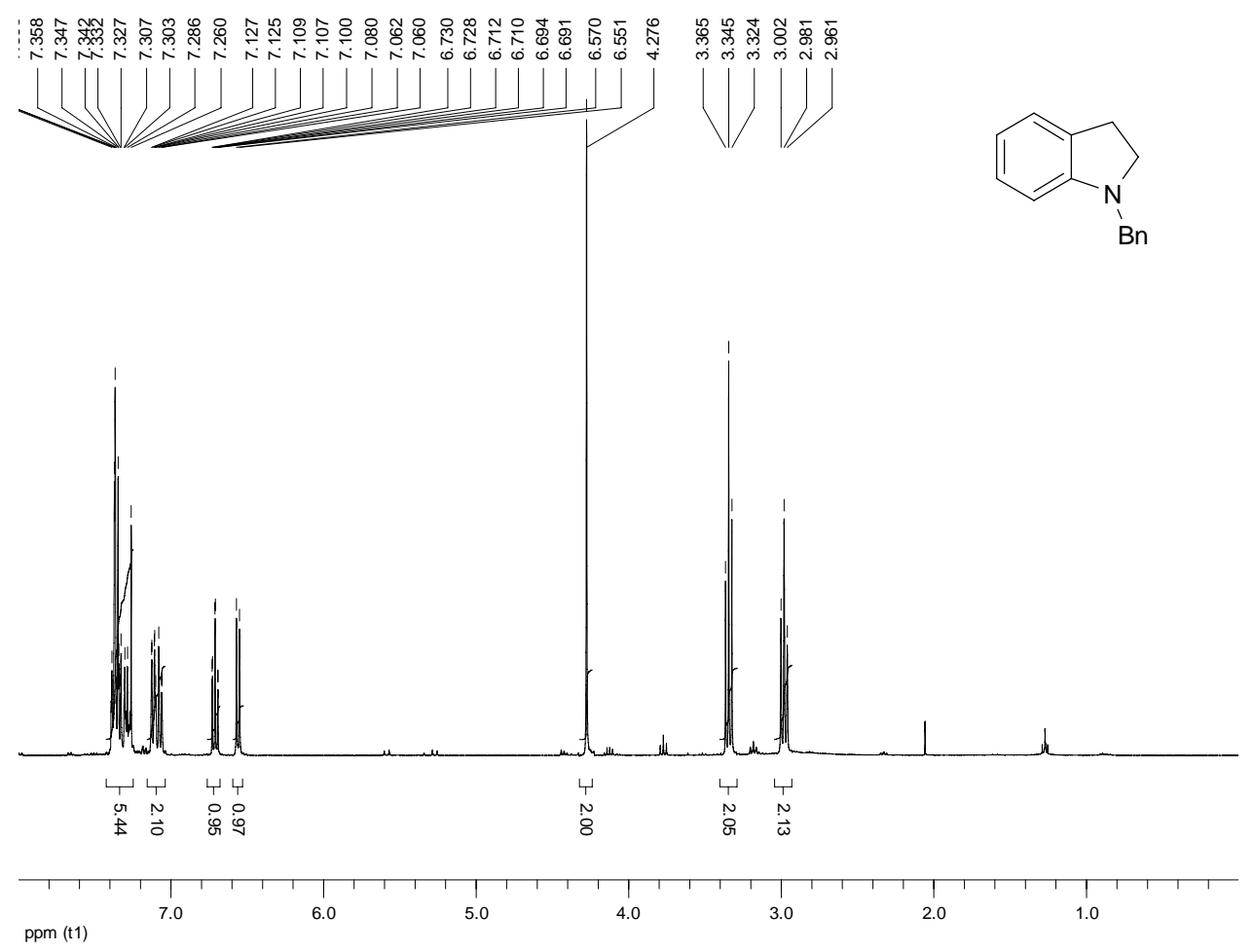


Product 11c, Table 4, Entry $3\left({ }^{1} \mathrm{H}\right)$

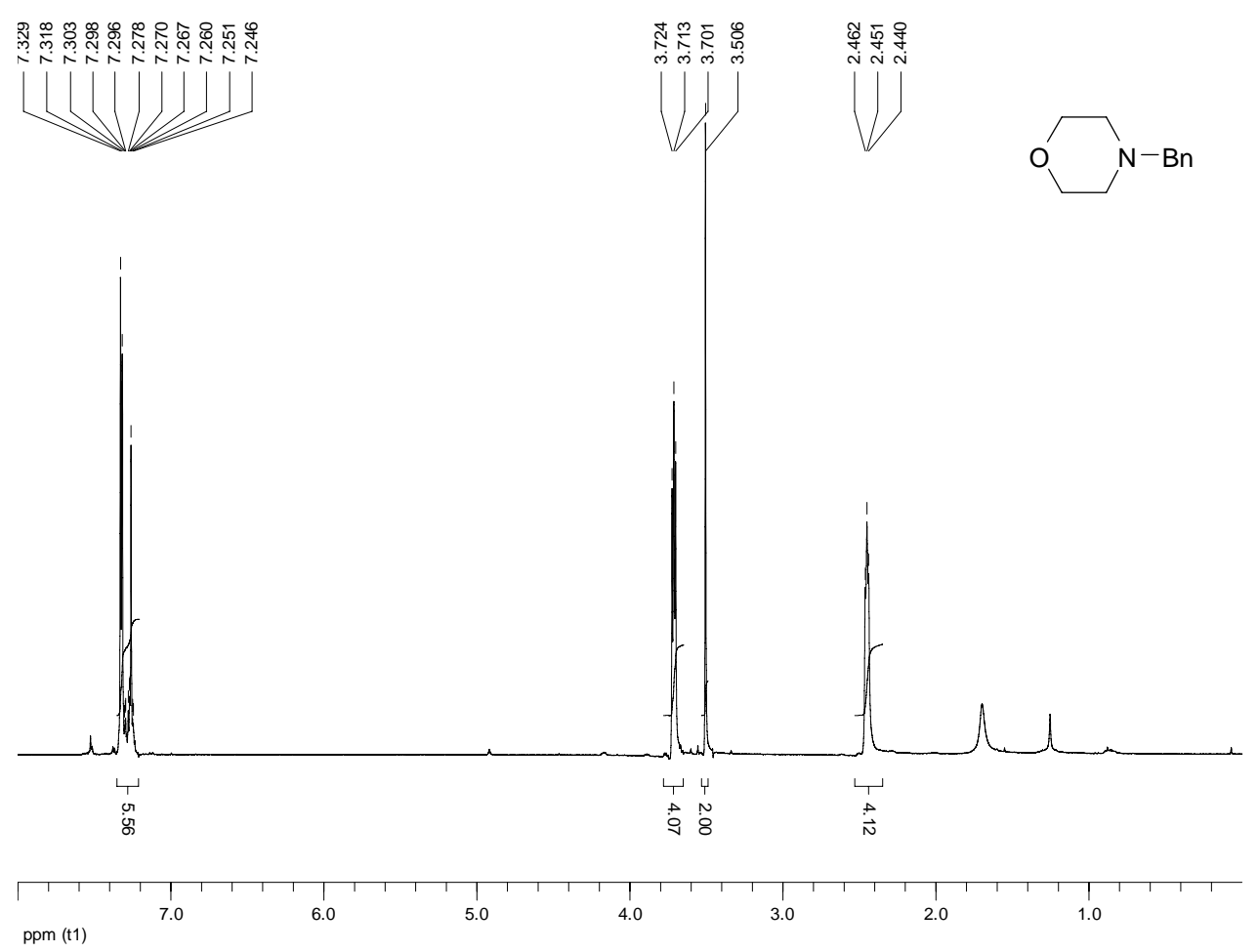

Product 11d, Table 4, Entry $7\left({ }^{1} \mathrm{H}\right)$

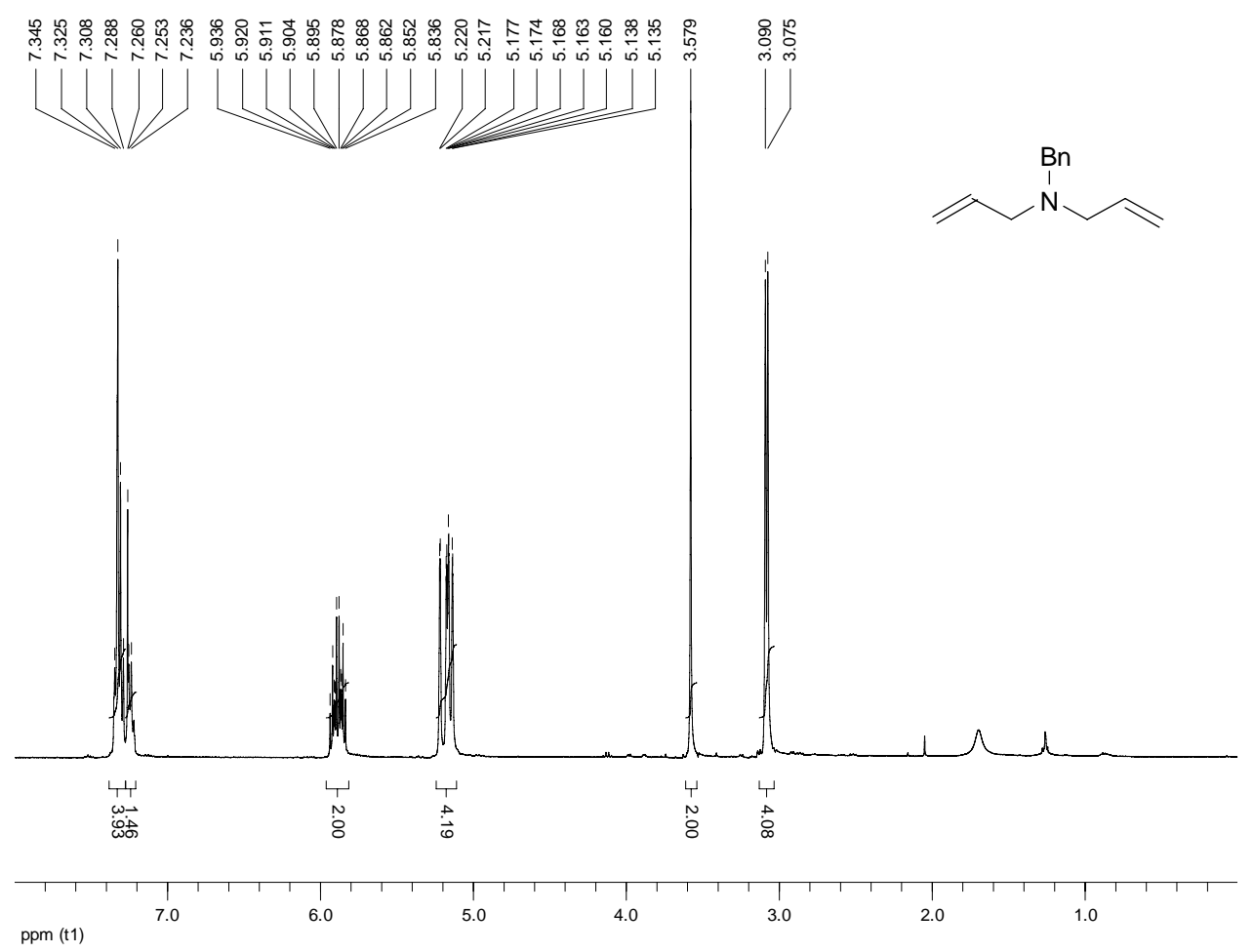


Product 11e, Table 4, Entry $8\left({ }^{1} \mathrm{H}\right)$

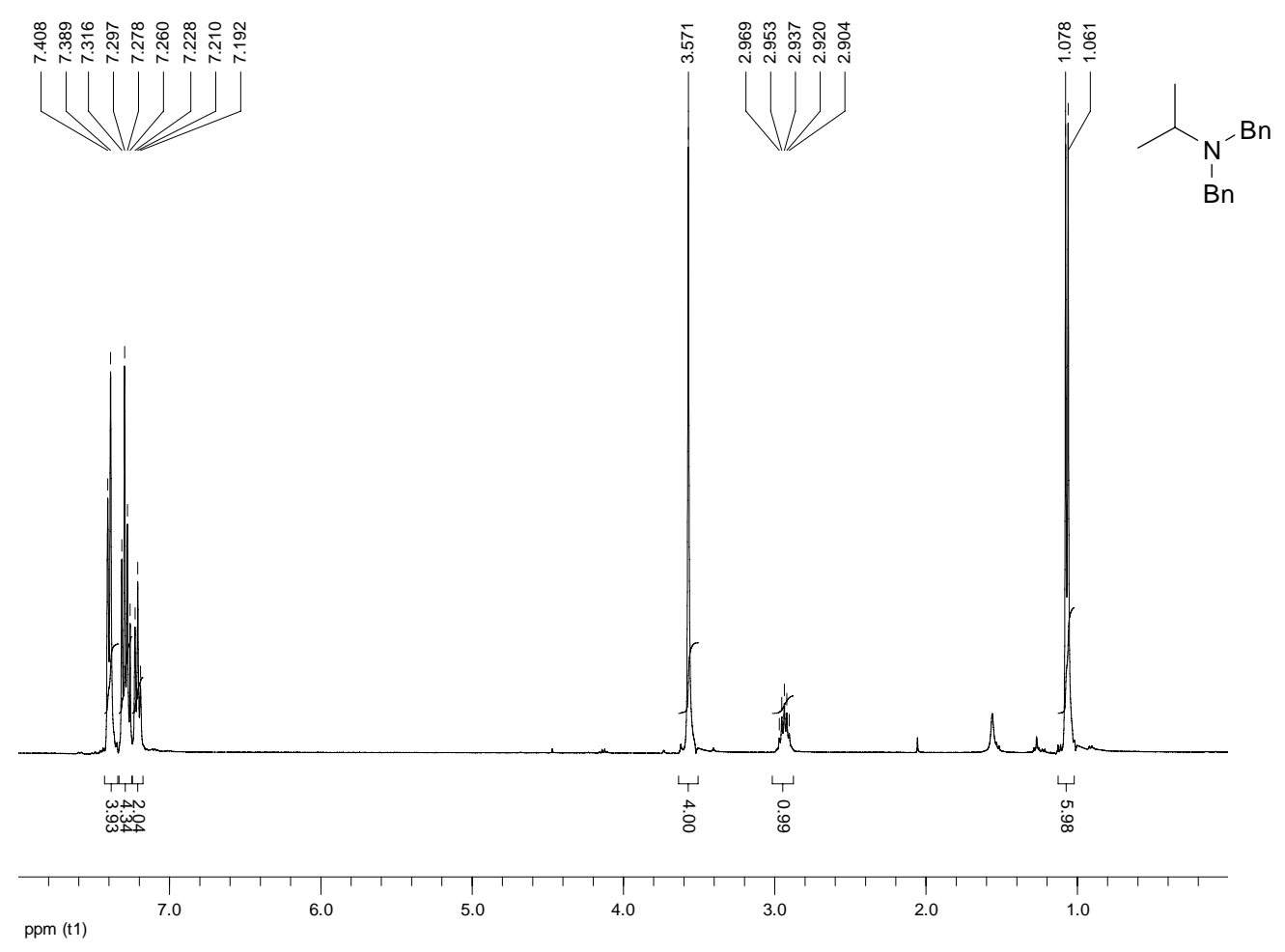

Product 12a, Table 5, Entry $2\left({ }^{1} \mathrm{H}\right)$
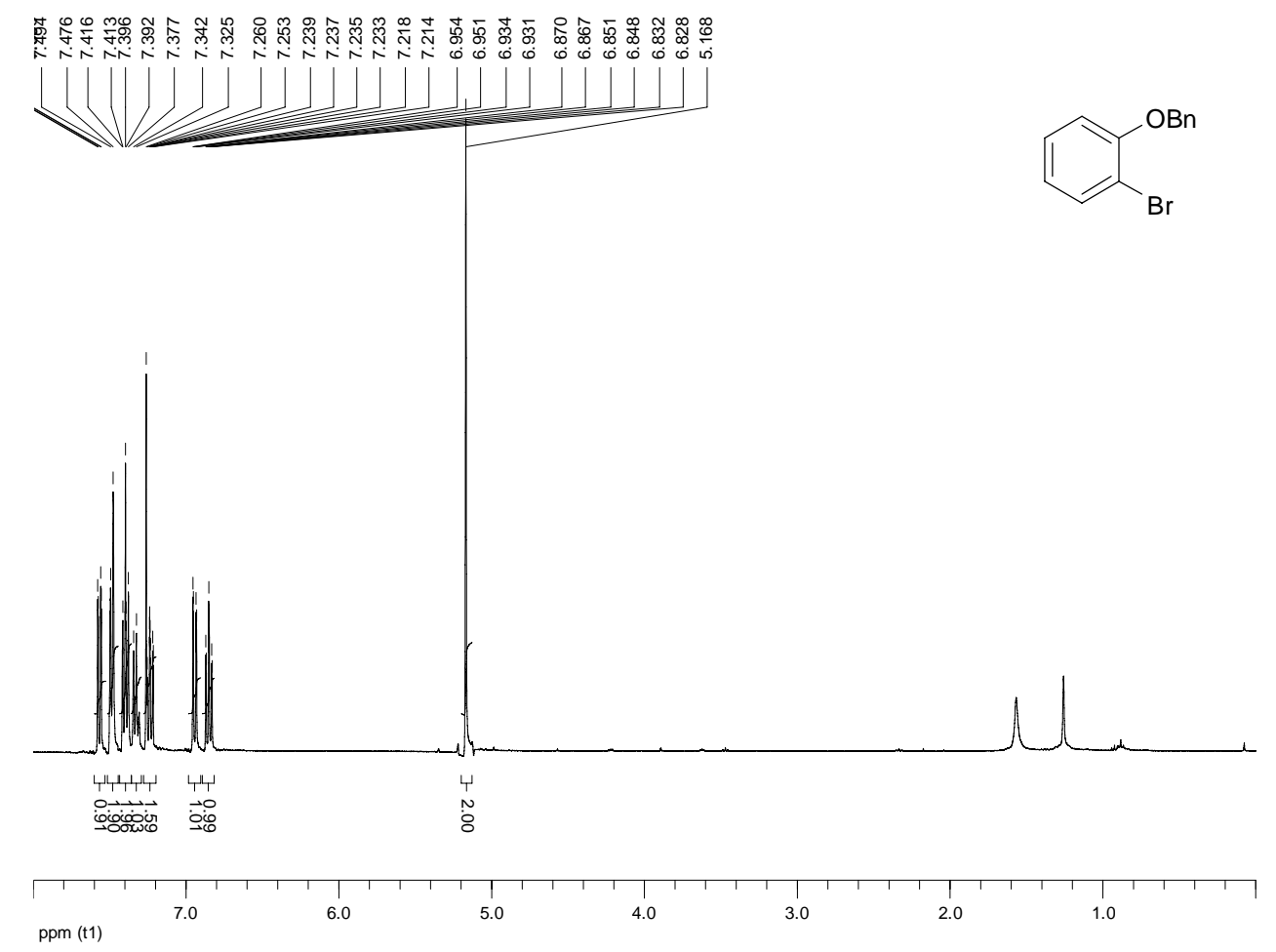
Product 12b, Table 5, Entry $3\left({ }^{1} \mathrm{H}\right)$

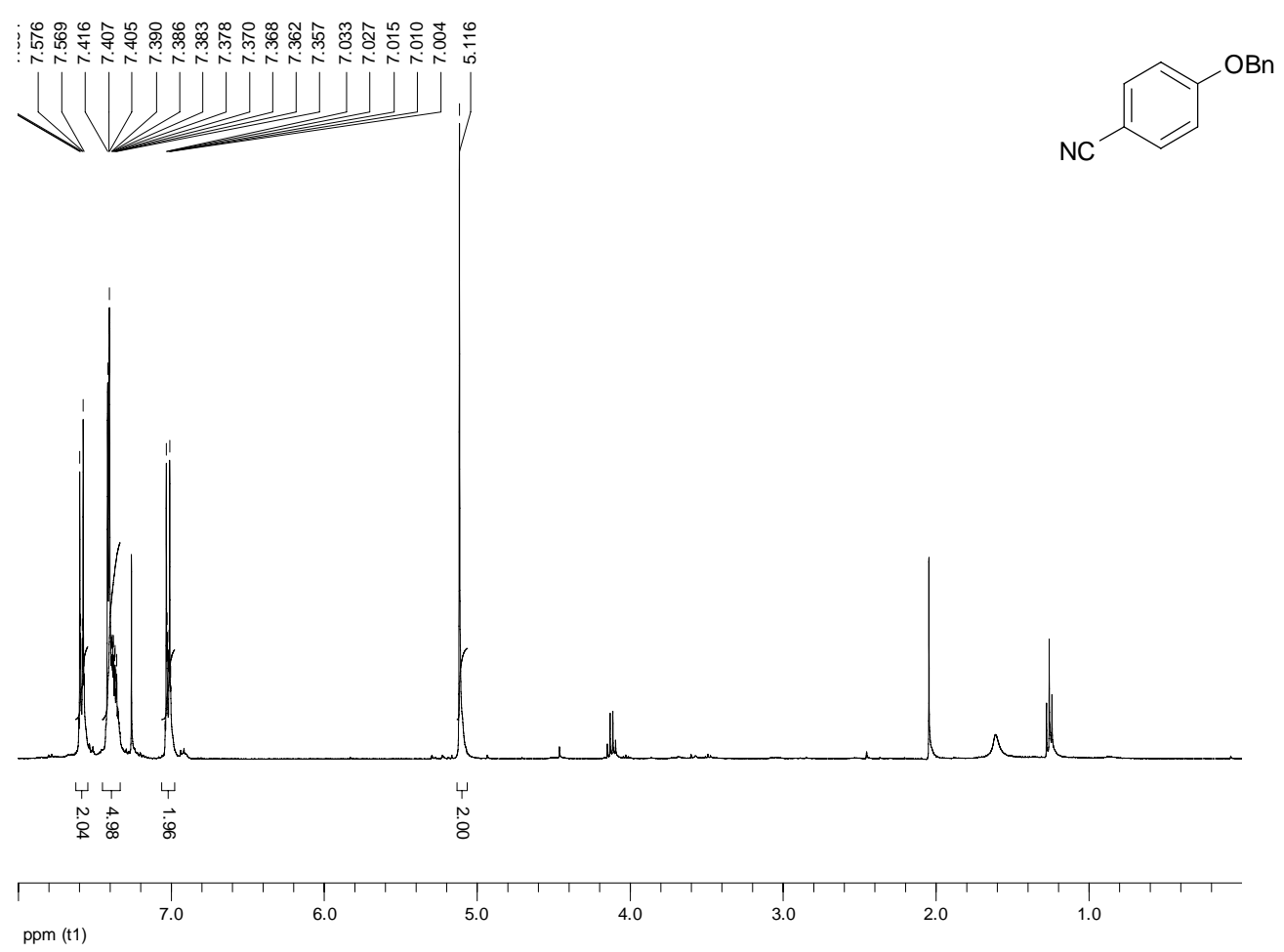

Product 12c, Table 5, Entry $4\left({ }^{1} \mathrm{H}\right)$

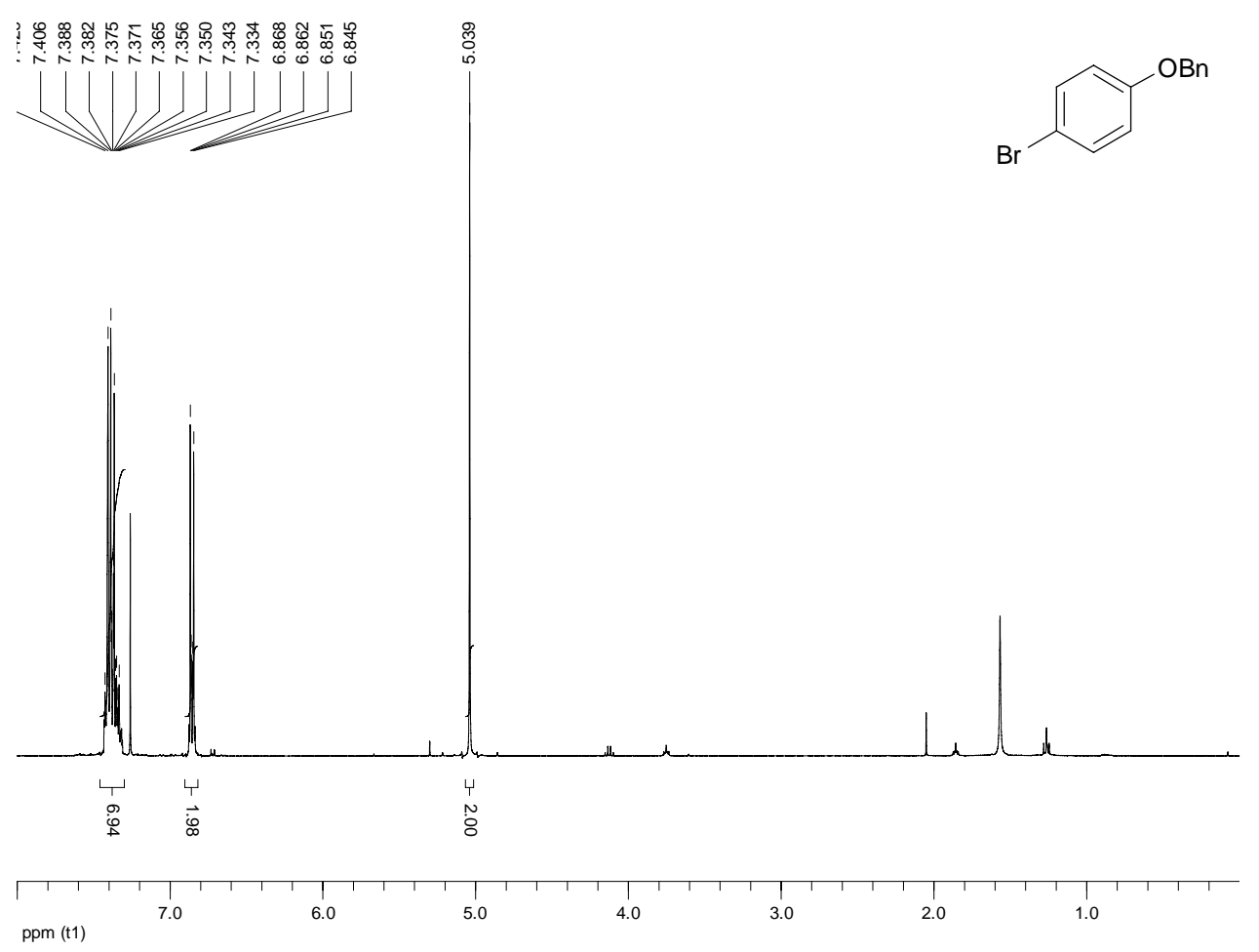


Product 12d, Table 5, Entry $5\left({ }^{1} \mathrm{H}\right)$

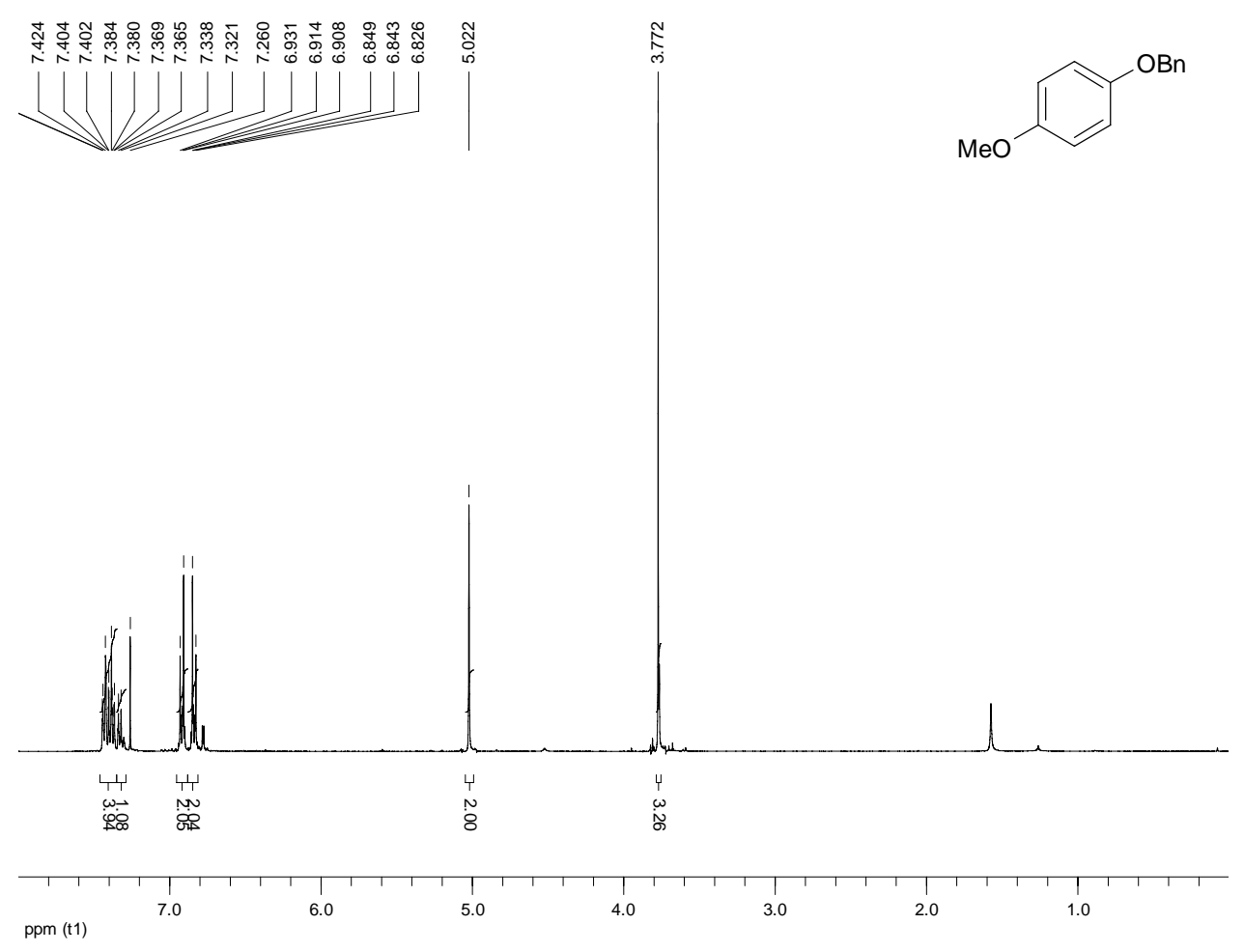

Product 12e, Table 5, Entry $6\left({ }^{1} \mathrm{H}\right)$

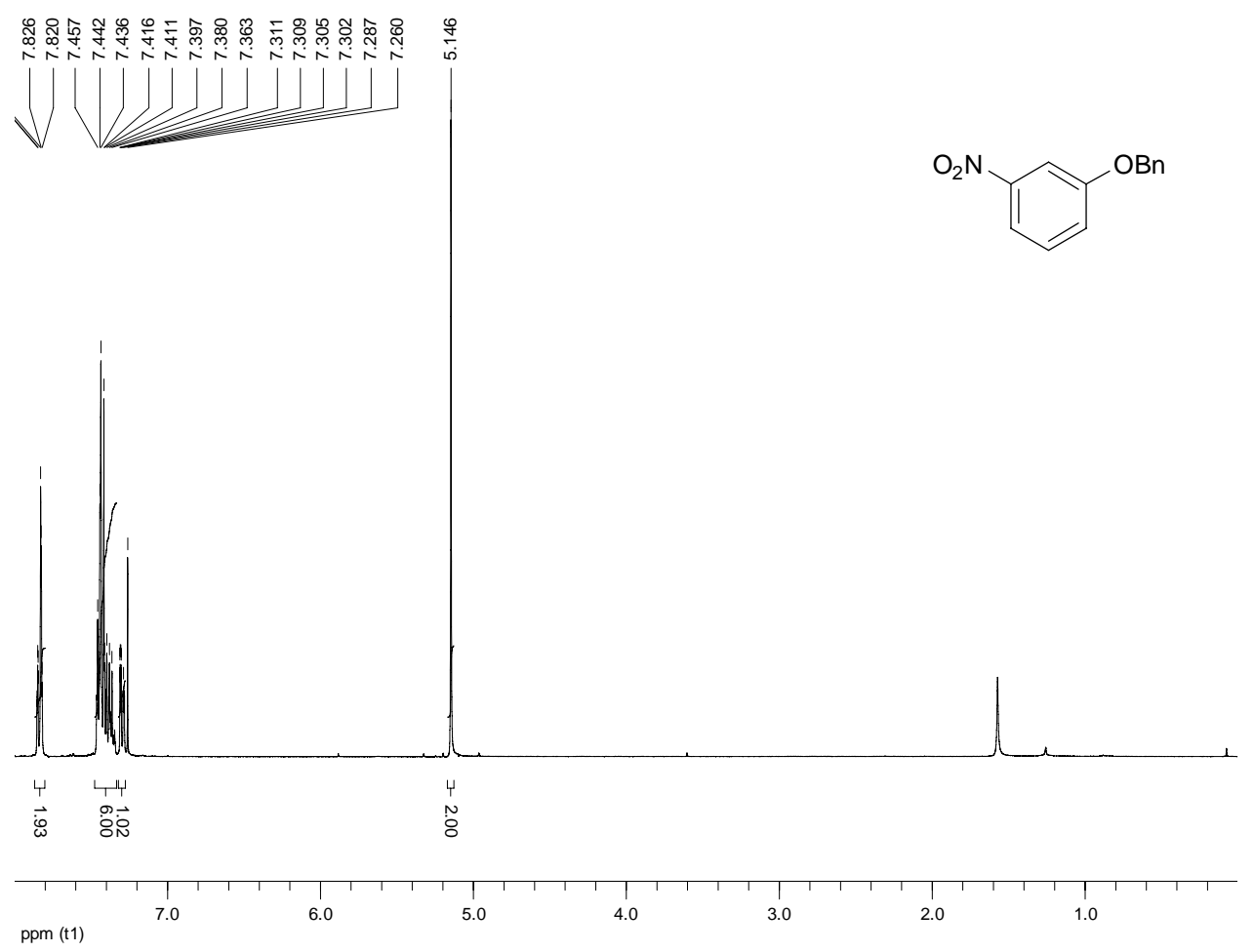


Product 12f, Table 5, Entry $7\left({ }^{1} \mathrm{H}\right)$

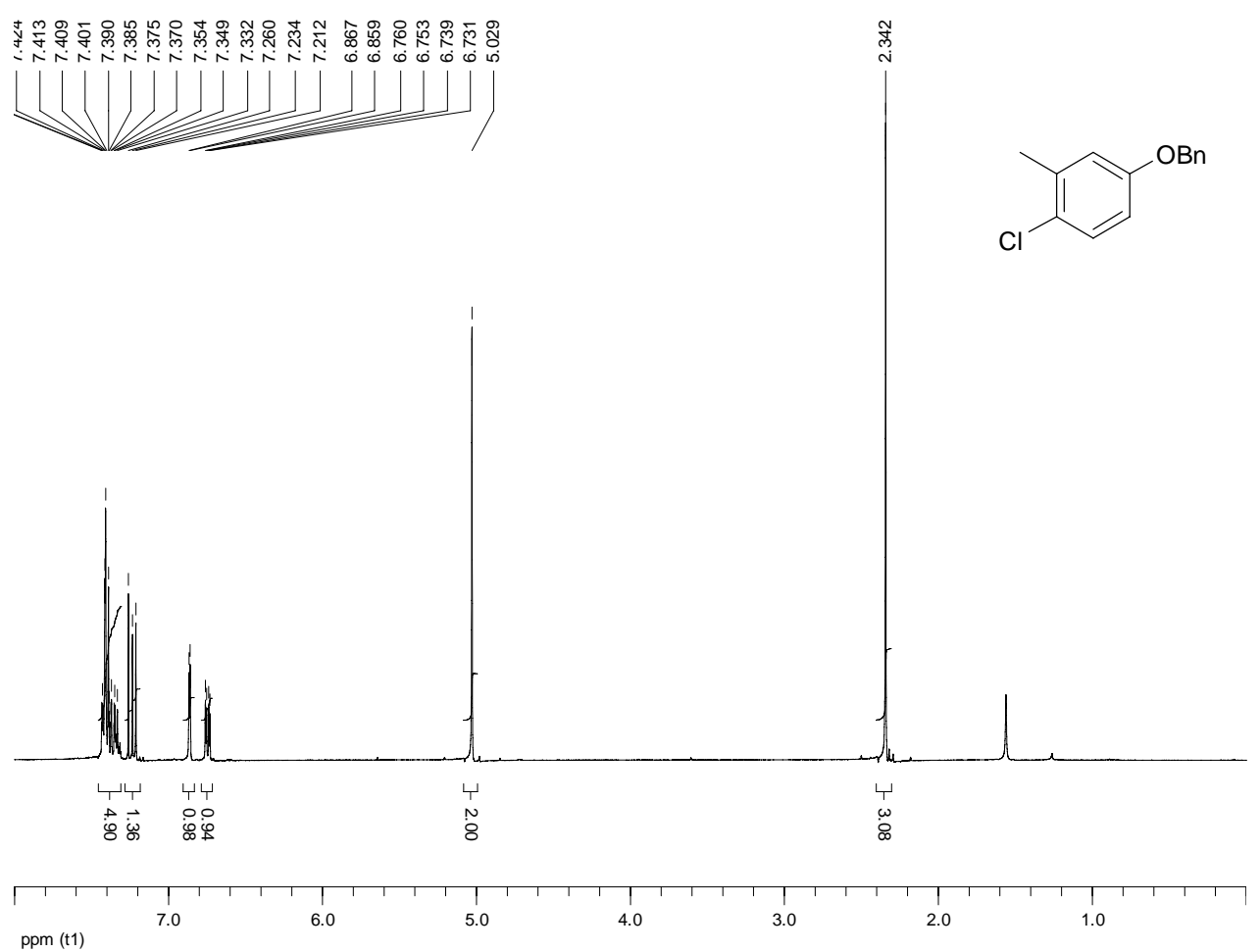

Product 12g, Table 5, Entry $9\left({ }^{1} \mathrm{H}\right)$

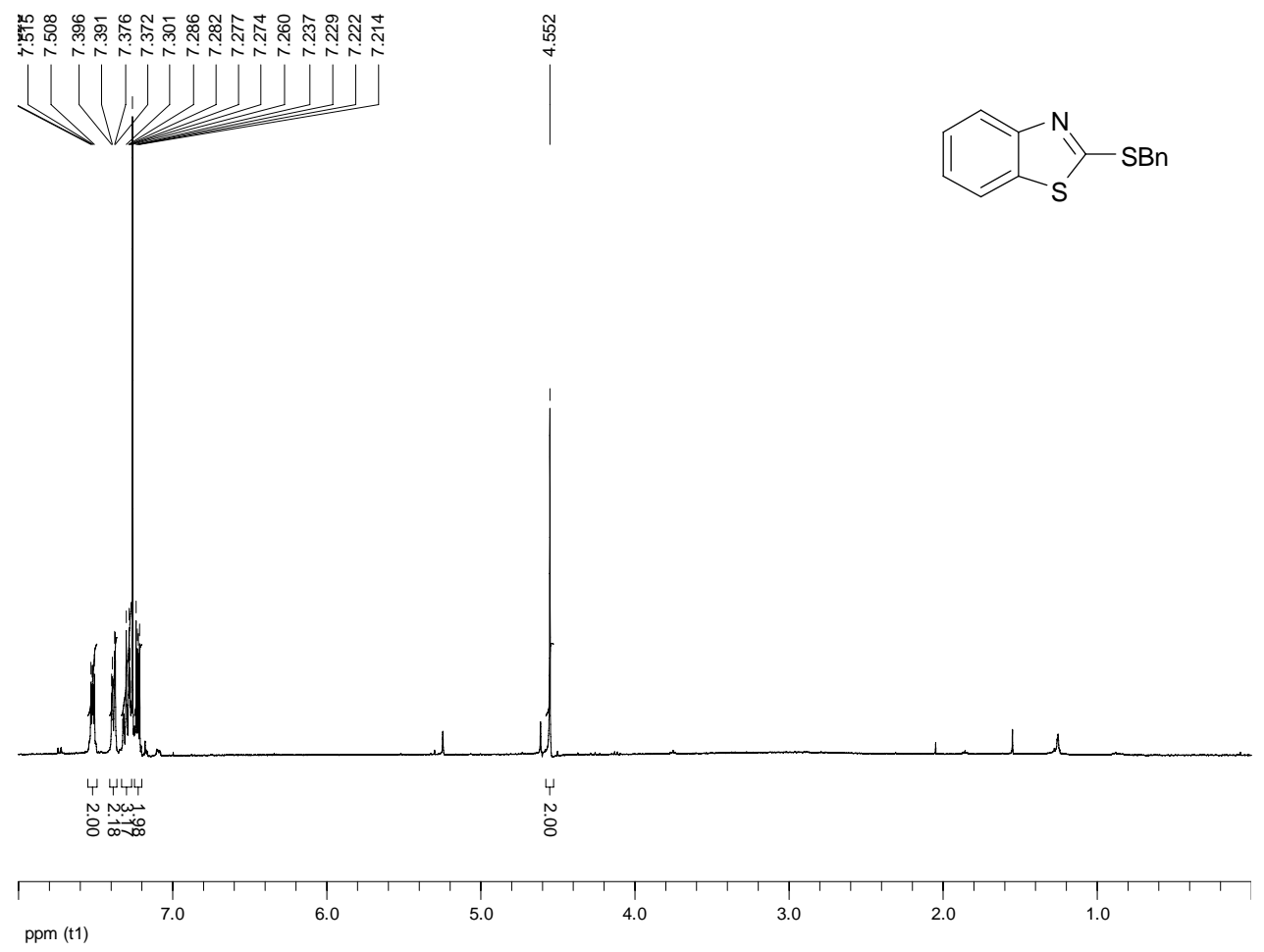


Product 12h, Table 5, Entry $10\left({ }^{1} \mathrm{H}\right)$

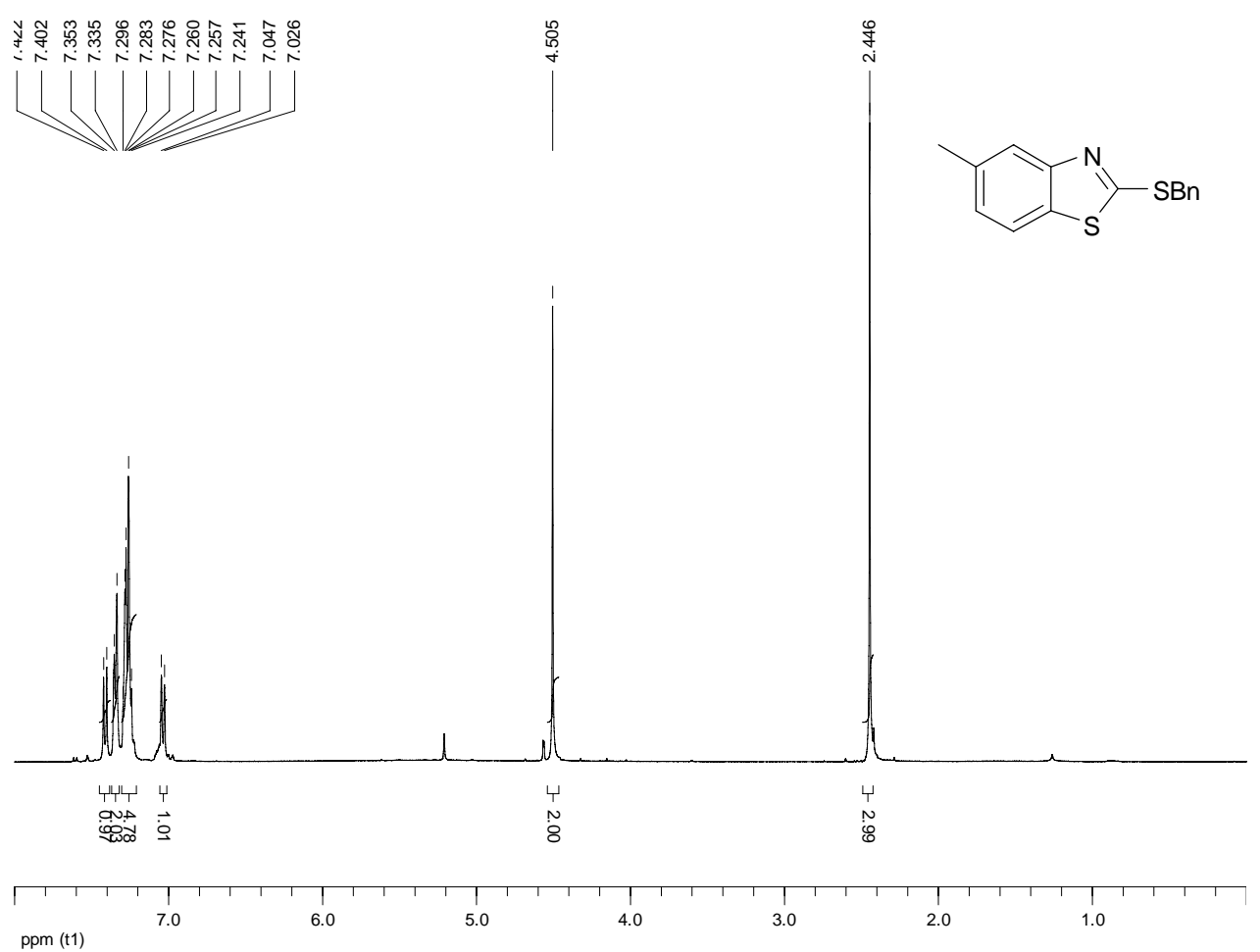

Product 12i, Table 5, Entry $11\left({ }^{1} \mathrm{H}\right)$

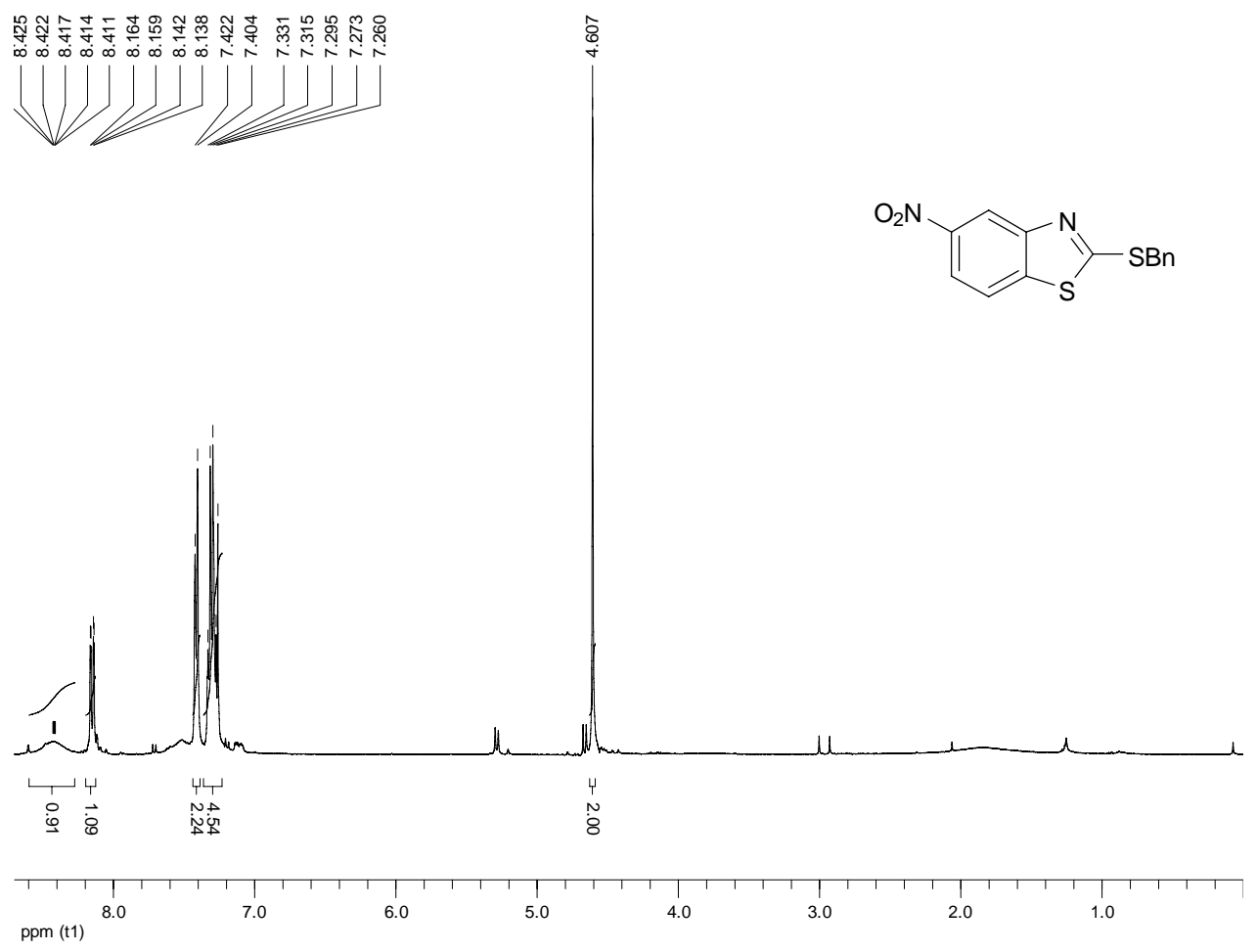

